\title{
The Renaissance of Bamiyan (Afghanistan) and Some Proposals for the Revitalisation of the Bamiyan Valley
}

\author{
Claudio Margottini, Andrea Bruno, Nicola Casagli, Giacomo Massari, \\ Heinz Rüther, Filippo Tincolini, and Veronica Tofani
}

\begin{abstract}
The present proposal have been developed by taking into consideration the need of an integrated and sustainable development of the whole Country as well as of the local Bamiyan community. In this view, the revitalization of Bamiyan valley must be integrated in a wider perspective, defined "downstream approach", that has been starting from the southern branch of the Silk Road, including Jam, Band-iAmir, Bamiyan and Shar-i-Zohak. The present proposal(s) are then a first step in cultural development of the country, where the Silk Road is the ideal and physical backbone of such model. The proposal is composed by an overall/modular approach with fixed elements (mitigation of soil erosion in Shahr-e-Zohak, rehabilitation of the many minor sites in Kakrak, reconstruction of the bazaar in front of the Great Western Buddha, revitalization of Shahr-e Gholghola, removal of fragments of the Statues still in front to the niche, little museums in front to each niche) and four alternative solutions for the valorization of niches. The latter varying from empty niches to temporary reconstruction with local marble/stone realized with anthropomorphic robots.
\end{abstract}

Keywords Bamiyan · Iconoclasm · Buddha statues · Valley and niches · Modular approach $\cdot$ Valorization

Published jointly by the United Nations Educational, Scientific and Cultural Organization (UNESCO), 7, place de Fontenoy, 75007 Paris, France, the UNESCO Office in Kabul, ICON Compound, Supreme Road, Off Jalalabad Road, PD 9, Kabul, Afghanistan, and Springer Nature Switzerland AG, Gewerbestrasse 1, 6330 Cham, Switzerland.

C. Margottini $(\bowtie) \cdot N$. Casagli $\cdot$ V. Tofani

UNESCO Chair for Prevention and Sustainable Management of Geo-hydrological

Hazards, University of Florence, Florence, Italy

e-mail: claudio.margottini@unifi.it

\author{
A. Bruno \\ Studio Bruno, Torino, Italy \\ G. Massari · F. Tincolini \\ TORART, Carrara, Italy \\ H. Rüther \\ Zamani Project, Cape Town, South Africa
}




\section{An Overall Approach to Conservation and Presentation of the Property}

\subsection{Foreword: Cutting the Root of Culture}

The iconoclasm (literally icon-breaking), widely practiced in all the countries of the world during its history, had already been hardly suffered by the Buddhas of Bamiyan, who at the end of the nineteenth century had been damaged by the artillery of the Afghan army with the use of the guns of the time, which, though not much powerful, they succeeded in harming the legs of the Great Buddha.

Unlike the first destruction of 1920 that had not caused any emotion, not being highlighted by the press of the time, the second terminal devastation, which occurred in 2000 , has been widely exalted and politically exploited by mass media throughout the world.

The Taliban were not the first Muslims to destroy monuments of the Buddhist religion that have disappeared under the impulse of Islam. Islam forbids any form of idolatry. For this reason, the generals of the Afghan army felt authorised to launch the artillery on the niches dug in the cliff, containing the idols to be demolished.

At the end of the year 2000, a dramatic anticipation of the future iconoclastic destruction (which will be repeated outside of Afghanistan with the destruction of the Twin Towers of New York) has completed the final avnd total cancellation of the deprecated Buddhist idol placed inside the niches that had been dug in the mountain to protect them.

Terrorism has lashed out not only against monuments but also against individuals. Commander Massoud, absolute symbol of Afghanistan's freedom from Soviet occupation, was vilely killed at the hands of a suicide bomber who blew himself up with him in the same mountains of his Afghanistan.

Several hypotheses of intervention were described in detail in the recent International Symposium on the Future of the Buddha statues held in Tokyo and earlier during the 2013 Orvieto (Italy) Workshop.

Many hypotheses of reconstruction, revitalisation of the site, virtual reconstruction and high-resolution projection were developed since 2001 and even implemented in the case of a projection in 2015 . The reason for such projects was mainly laying in the idea to give back an identity to a population that had been deprived of his historical and cultural identity. Some of these projects are reported in Fig. 1.

In recent years, iconoclasm has been deliberately designed to make the expanding of these terrorist armies spectacular, due to the global audience, but also to annihilate the local populations. In fact, devastations tend to cut the roots of peoples with their history and their traditions, making them orphans of their culture and, therefore, easy prey of fundamentalism.

It is undoubted that the cancellation of a common history weakens the sense of belonging of a people to its territory. That's exactly what happened in Afghanistan where, for over 1500 years, about 800 of which after the presence of Islam in the country, the Hazara jealously guarded the Buddhas of Bamiyan, considering them a 

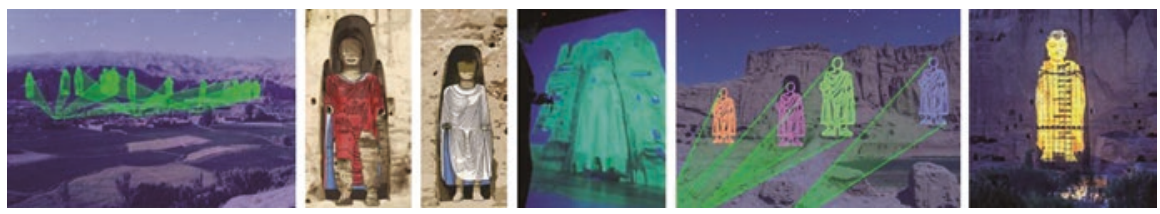

Fig. 1 Proposals on the web for virtual reconstruction and high-resolution projection. (@) Claudio Margottini)

common heritage of their history. In fact, they refused to destroy the statues in 2001, and external people had to intervene, blasting the heritage.

One of Andrea Bruno's proposals, immediately following the destruction by the Taliban, was the creation of a large two-dimensional fibreglass panel, size 1 to 1 , placed in the niche of the missing Buddha, to reproduce photographically its image in real size. This project aimed to cancel as soon as possible the shocking emotion that the destruction had produced throughout the world and especially among the Bamiyan population, who considered those Buddhas an essential part of the natural landscape of the Valley. This was a temporary solution but nevertheless a sort of revenge on the Taliban fury and a chance for the Bamiyan population to see the effigies of the two Buddha statues again at their usual place in the panorama of the cliff. These statues suddenly disappeared within the niches that today are dominated by their absence. This solution, therefore, according to Andrea Bruno, was the only short-term possibility of "recreating" the missing heritage.

After the destruction of giant Buddha statues, the scientific community started to investigate how to give back, to Afghanistan and to the Azar local community, a masterpiece of their history and tradition, clearly being aware that only $12 \%$ of original surface can be recovered and only $11 \%$ of original volume was not decomposed into debris and dust (Toubekis et al. 2017).

The exceptional beauty of the Buddhas obtained by carving an entire rocky wall of a mountain and, later on, literally reduced to dust due to the precise order of Mullah Omar can hardly be recreated. Nowadays, any possibility of reassembling the original pieces (anastylosis) is excluded, showing how irreversible this iconoclastic work has been.

Since then, no clear ideas on how to revitalise the entire area and cliff have been proposed in a convincing manner. The delay in making the decision to restore the area at the foot of the Western Buddha, and the lack of a proper management on the remaining fragments, has also provoked highly undesirable effects due to the negative image that these debris give to the cultural landscapes. All this served only to magnify the impact of destruction since 2001.

After the destruction (Margottini 2004), the restoration must inevitably represent the continuation of life (Margottini 2014). There are today many approaches, and the huge technological progress made it possible to reconstruct every work of art created by the human hand, making it absolutely indistinguishable from the original. The recent reproduction of Michelangelo's Pietà with robotic instruments is particularly significant (www.torart.com). 
However, in Afghanistan, today, there are certainly more urgent priorities and some interventions to be done on the territory and other monuments of the Valley. One of the interventions accomplished by Japan in the area, for example, has been the restoration of all the wall paintings that have been definitively "musealised" and are available today for tourists. The intervention has been significant from a scientific, historical and artistic point of view.

The Valley of Bamiyan and its inhabitants are and will remain a primary goal of the cultural policy of UNESCO and of those working in the cultural field. For this reason, what has been said in this article has to be considered as just the beginning of a long series of considerations which started long time ago, which is never interrupted and which will continue indefinitely through history.

\subsection{An Overall Approach to the Valley and Niches}

The present proposal has been developed taking into consideration the need of an integrated and sustainable development of the whole country as well as of the local Bamiyan community. In this view, the revitalisation of Bamiyan Valley must be integrated in a wider perspective, later on defined "downstream approach", that has been starting from the southern branch of the Silk Road, including Jam, Band-eAmir, Bamiyan and Shahr-e-Zohak. The present proposal(s) is then a first step of a country cultural development, where the Silk Road is the ideal and physical backbone of such model (Fig. 2).

The same holistic approach has been used for the Bamiyan Valley. In fact, the present concept-project defines a series of subprojects, in the Valley, that are common to the various proposals for the physical revitalisation of the niches. Such subprojects have been reorganised starting from the experience of Andrea Bruno in the last 55 years and more recently of Claudio Margottini (Fig. 3) (Margottini 2007, 2009a, b, 2014, 2015a, b; Crippa et al. 2013).

They include:

1. Reconstruction of the bazaar that, before the war, was standing in front of the Great Western Buddha (Fig. 4). The major difficulty in this subproject regards the management of land properties.

2. Realisation of a museum in front of both niches (Fig. 5).

3. Revitalisation of Shahr-e Gholghola (Fig. 6). Three of the existing caves can become a point of social aggregation.

4. The realisation of an underground museum in front of the Western Great Buddha (Fig. 7). This museum can be realised by simply covering part of the existing excavation. An open hole in the roof will allow the view of the niche. Inside the museum, a reconstruction of the Buddha statue will allow visitors to understand the magnificence of the lost heritage. 


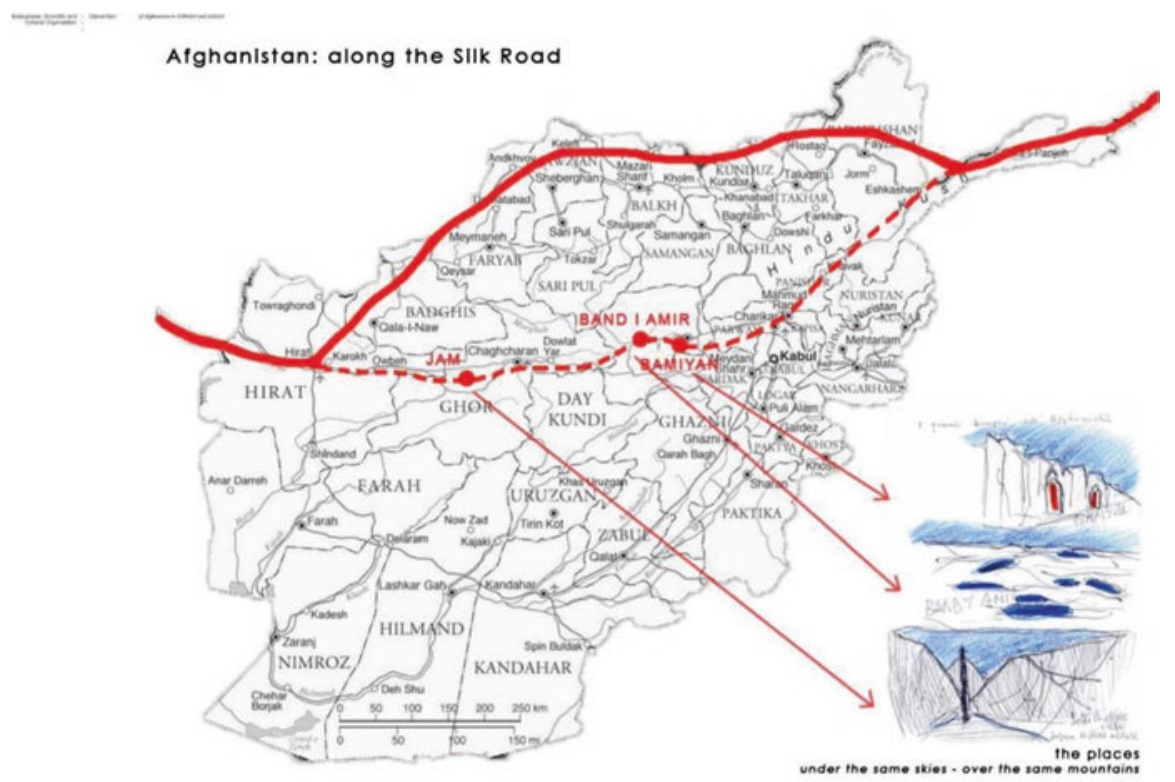

Andrea Bruno

Fig. 2 A "downstream approach" for the revitalisation of Bamiyan Valley starting from the redevelopment of Silk Road. () Andrea Bruno)

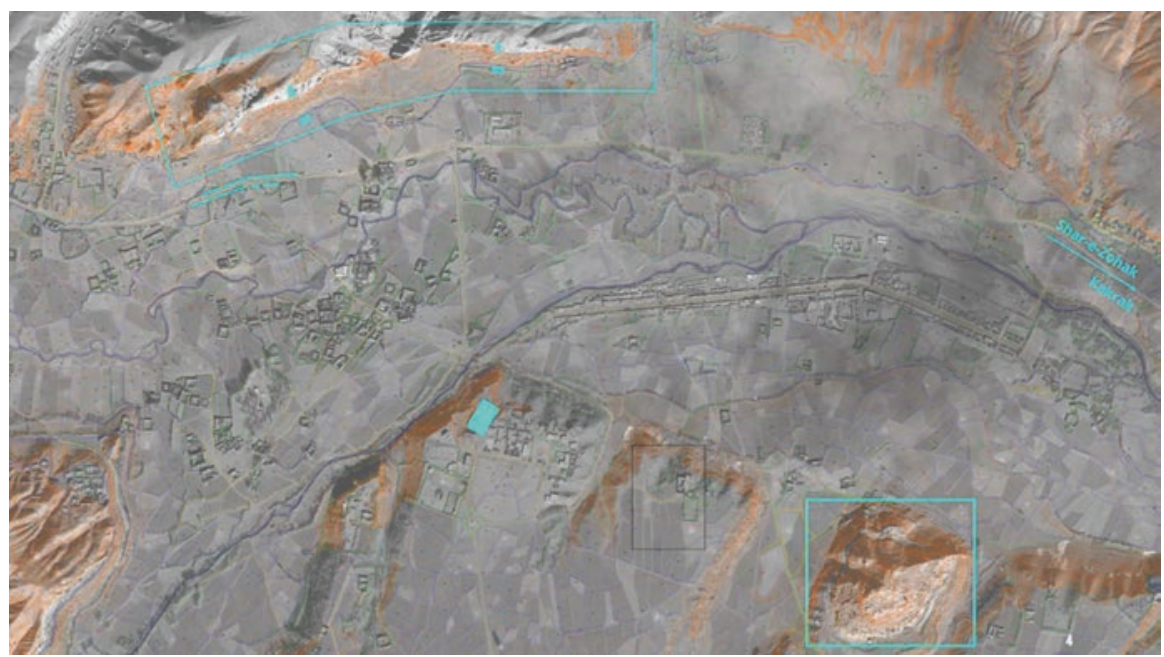

Fig. 3 Geographical distribution of the subprojects that are ancillary to the revitalisation of Eastern Buddha niche. (@) Claudio Margottini) 

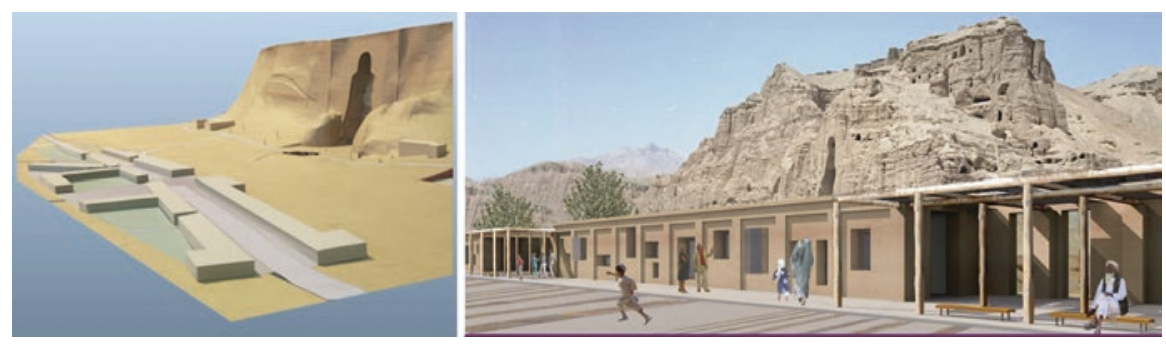

Fig. 4 Reconstruction of the bazaar in front to the Great Western Buddha. (Project Andrea Bruno) (C) Andrea Bruno)
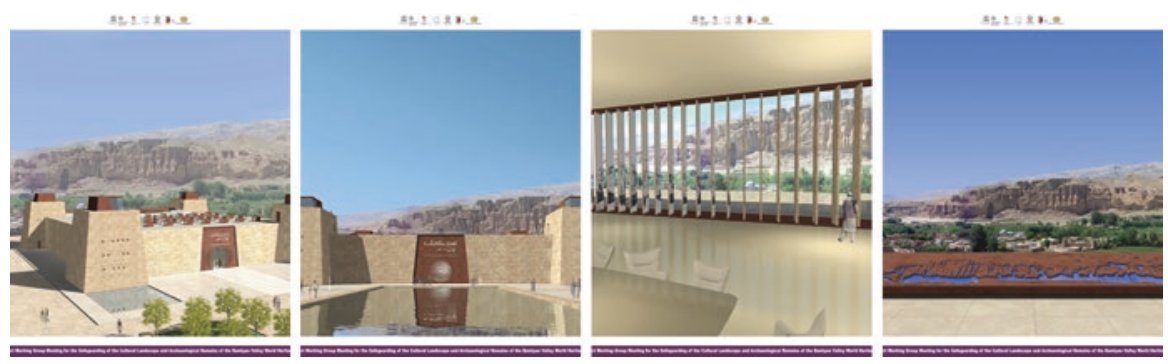

Fig. 5 The large museum in front of both niches, on the other side of the valley. (Project Andrea Bruno) (@ Andrea Bruno)
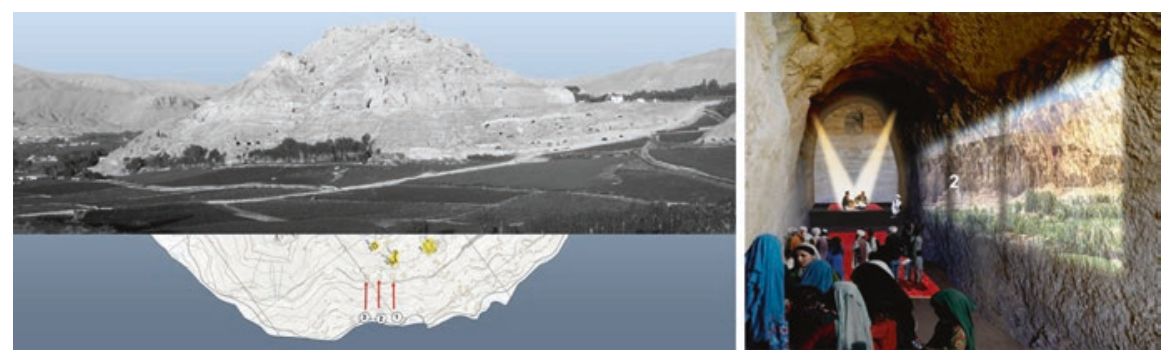

Fig. 6 Revitalisation of Shahr-e Gholghola. (Project Andrea Bruno) (๔ Andrea Bruno)

5. Mitigation of soil erosion in Shahr-e-Zohak and recovering of existing "red fortress" (Fig. 8). The remains of the Shahr-e Zohak fortress are located on a steep hill at the confluence of Kalu and Bamiyan rivers, about $15 \mathrm{~km}$ east of the city of Bamiyan (Central Afghanistan). The site is thought to have been built during the Buddhist period (sixth-seventh century A.D.), even if the fortification is dated to the Islamic period. Its position provided both excellent natural defences and control over the valleys as important communication routes. The site is affected by heavy soil erosion that has been damaging also the structures. A conservation project was presented in 2013 (Margottini et al. 2015). 

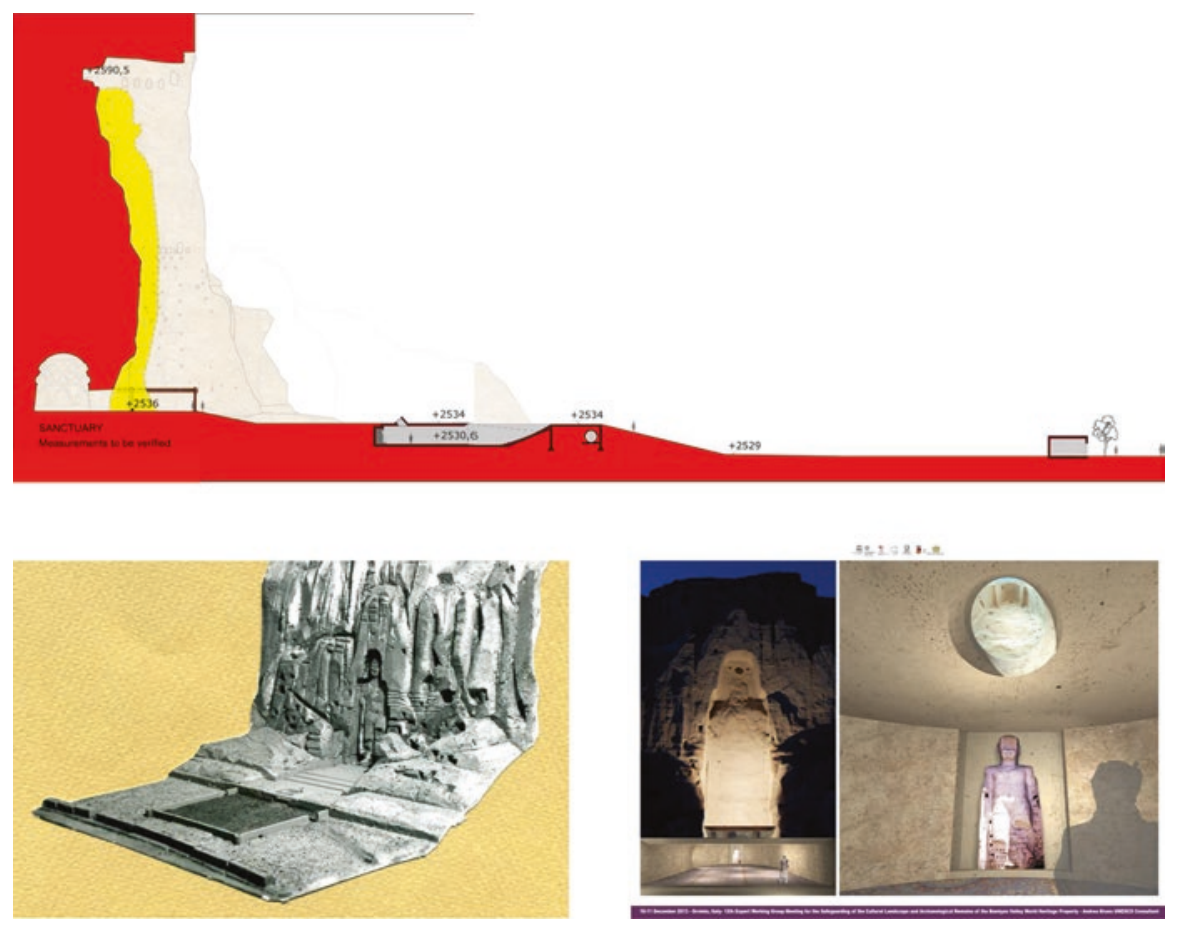

Fig. 7 The realisation of an underground museum in front to the Western Great Buddha. (Project Andrea Bruno) (@) Andrea Bruno)
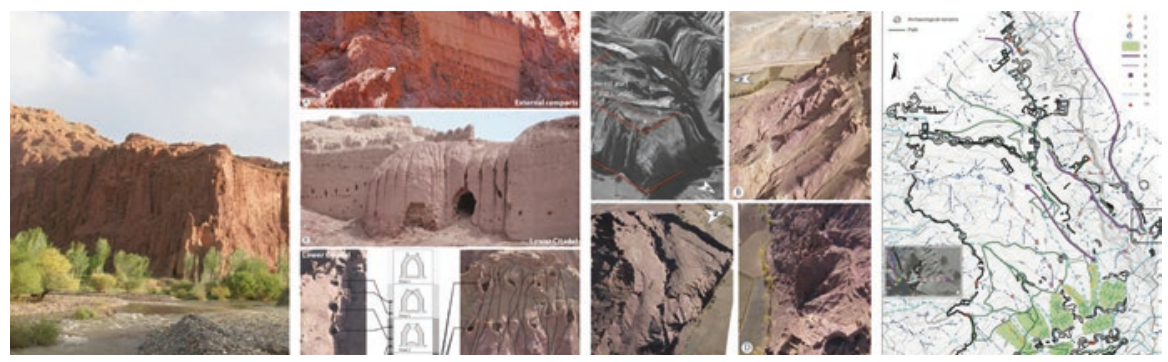

Fig. 8 Mitigation of soil erosion in Shahr-e-Zohak and recovering of existing "red fortress". (Project Claudio Margottini) (Margottini et al. 2015) (@) Claudio Margottini)

6. A rehabilitation proposal of the many minor sites, such as in Kakrak, can be considered (Fig. 9). In this site, it might be possible to realise a copy of existing statue, using the same technology presented in the following proposal nos. 3 and 4 . 

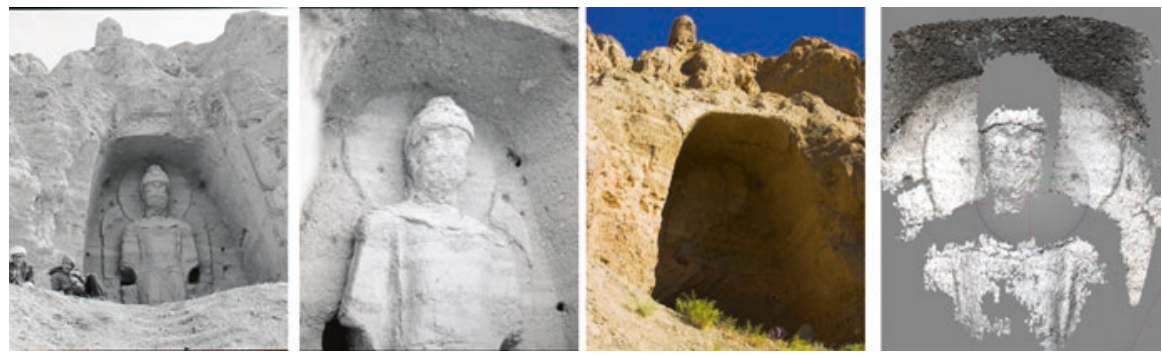

Fig. 9 Rehabilitation of the many minor sites, such as in Kakrak, with a 3D reconstruction of the statue and a possible rock reconstruction. (@) Claudio Margottini)

The final step of our proposal will be the revitalisation of the Buddha niches, in this case the Eastern Buddha niche as requested by UNESCO. The revitalisation should consider either physical revitalisation or non-physical revitalisation inside the niche, in order to provide the Government of Afghanistan with a balanced range of options, reflecting the diverse spectrum of opinions about revitalisation. Physical revitalisation implies rebuilding the Eastern Buddha statue. Non-physical revitalisation implies, instead, taking measures to interpret the Eastern Buddha statue without any physical form during statue reconstruction.

The inspiring principle is that the heritage in Bamiyan should highly contribute to (local) sustainable development, in a "downstream" perspective, from national (the Silk Road) to local level (Bamiyan Valley), as it has been described before. In this view, any solution we might propose for the revitalisation of the Bamiyan Cultural Landscape has to impact on the economic, social, cultural and environmental domains.

The general approach to the cliff is reported in the Fig. 10. Each niche has its own underground museum, focusing on the specific target, while a comprehensive view of the cliff, including a laser scanning and drone survey, will be displayed in the general museum, in front of both niches.

In more detail, the following action must be implemented before any intervention on the niche, according to the authors.

1. Removal of fragments. After 15 years from the blasting, fragments are still on the ground, and, along with some stores, they are currently degrading the overall landscape. The fragments should be collected and stored in a proper space, accessible for scientists, archaeologists and, hopefully, future restorers.

2. Surveying through laser scanning and drone. To be used for 3D augmented reality, in the Bamiyan museums and elsewhere.

3. Realisation of an underground museum in front of the Western Buddha niche. 


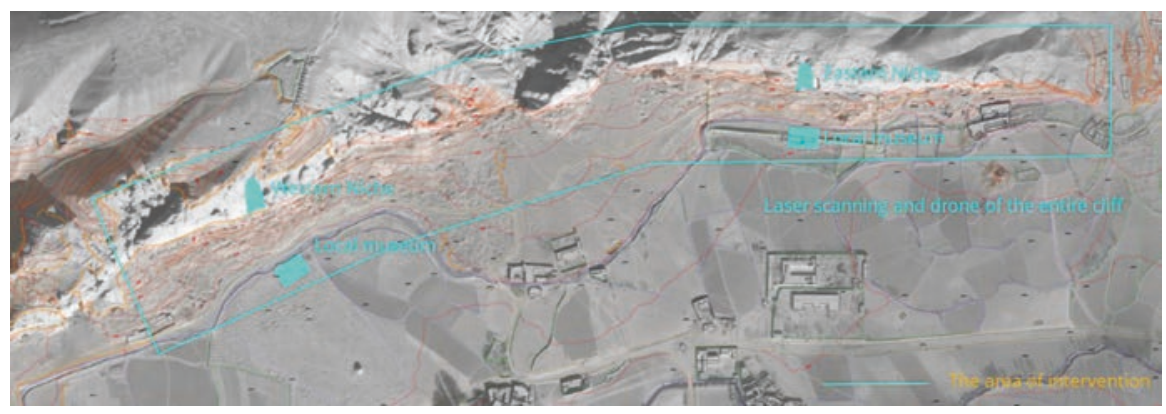

Fig. 10 The general approach to the cliff considering the clear-out of the fragments and delocalisation of the store, the geomatic survey of the cliff and the local underground museum in front to each niche. (@) Claudio Margottini)

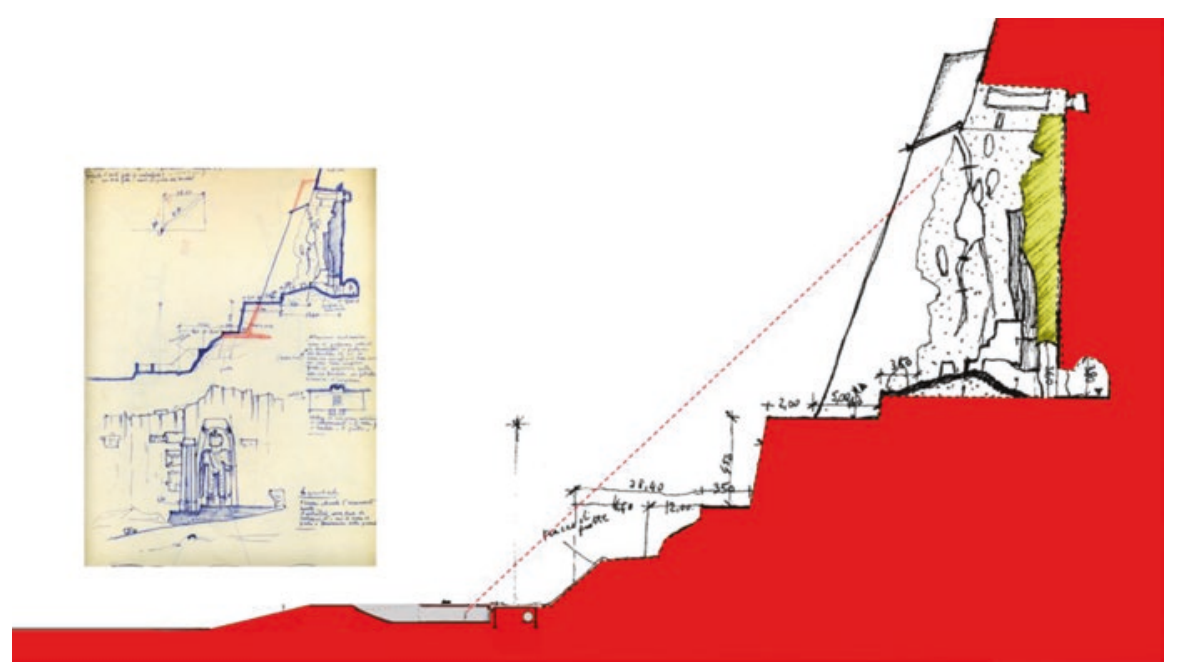

Fig. 11 The proposal for the underground museum in front of the Eastern Buddha niche. A preliminary hypothesis from Andrea Bruno in 1962 is also reported. (@ Andrea Bruno)

4. Realisation of an underground museum in front of the East Buddha niche (Figs. 11 and 12). Such structure will be similar to the one of the Western niche. As for the Western niche, an open hole in the roof will allow the view of the niche. Inside the museum, a reconstruction of the Buddha statue will allow visitors to understand the magnificence of the lost heritage. 

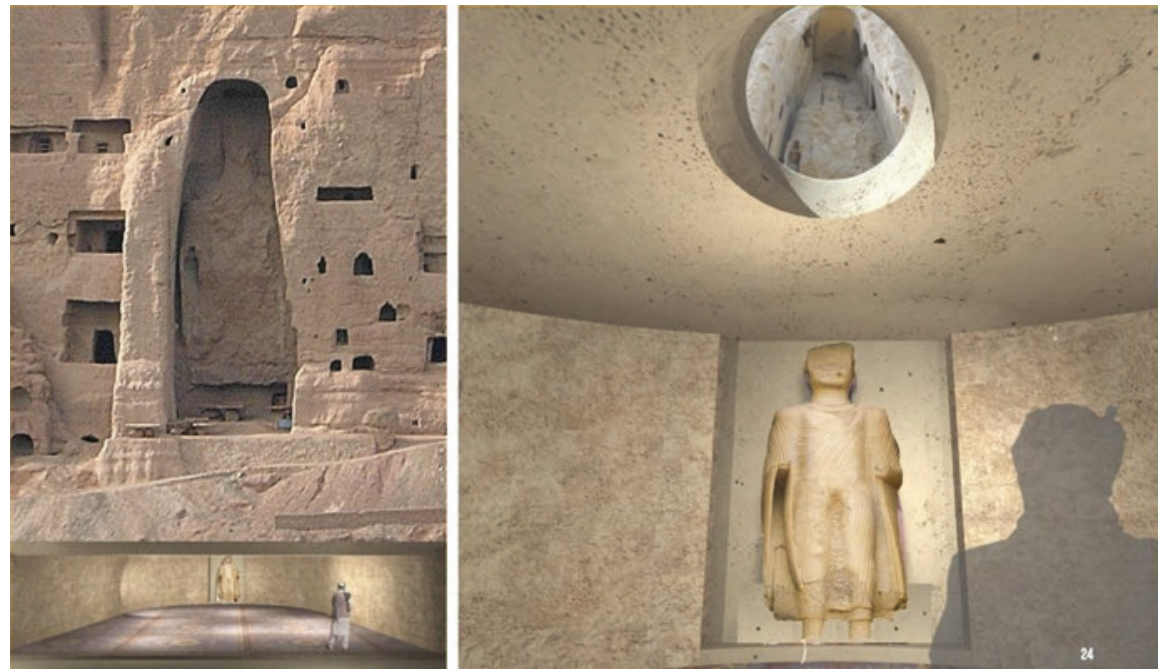

Fig. 12 The underground museum in front of the Eastern Buddha niche. (๑ Andrea Bruno)

\section{Into the Eastern Buddha Niche}

\subsection{An Appropriate Conservation Philosophy Based on the Outstanding Universal Value of the Property}

The Eastern Buddha niche is part of the "Cultural Landscape and Archaeological Remains of the Bamiyan Valley" which was included in the World Heritage List in 2003. Many criteria were used (i, ii, iii, iv and vi), describing the relevance of Gandaharan art in this region, the interchange of diverse religious and cultural traditions, the cultural tradition, the cultural landscape but also the direct and tangible association with a tragic, violent and deliberate destruction of irreplaceable cultural heritage in the twenty-first century A.D. As a consequence, the destruction is part of the OUV, and any physical revitalisation has to bear this in mind. This point was well established since 2003, during the nomination process, since it was very clear that most of original rock was pulverised ( $89 \%$ according to Toubekis et al. 2017), due to its low consistency, the vertical variability of rock mechanical parameters and the energy of blasting in a close environment that the niche is. Visibly, a large percentage of such remaining fragments comes from the interior of the statue, and, unfortunately, there is no record of the exterior surface of the statue. It must be also noticed that the remaining fragments, especially in the Eastern Buddha niche, were further weakened by the explosion, and it is not clear how they can be managed or utilised. As a conclusion no use of existing fragments is possible from a technical point of view but also in respect to the OUV represented by criterion (vi). A similar concept can be supported by the Charter of Venice and the possibility to have an 
anastylosis only when the original blocks are still in site and the regrouping is feasible.

Having the above physical constraints in mind, according to our view, any possible approach to the rehabilitation of the site has also to consider the following aspects:

(1) The chosen proposal does not have to place Bamiyan as a new target for terrorist attacks; to achieve this result, any solution has to be easily replicable, at low cost, thus discouraging the idea of an irreplaceable impact of terrorism action.

(2) The new parts should be easily distinguishable from the original cultural landscape.

(3) The landscape should not be altered.

(4) The proposed design should enhance the site at worldwide level, demonstrating the capacity of human beings to transform a tragedy into a jewel of art.

(5) The proposal must be fully reversible and not modify permanently the site; in this condition, no modification of integrity and authenticity is obtained and then maintaining the OUV of the original criterions. A question is still under discussion: What is the reference integrity and authenticity in Bamiyan? The present situation after the explosion or the original?

(6) The proposal must be temporary, giving the chance and the time to study, in the future, possible alternative solution in the revitalisation of the entire site.

(7) The proposal should not diminish the relevance OUV represented by criterion (vi) approved in the World Heritage Committee on 5 July 2003.

(8) Any physical intervention should be identifiable with respect to original archaeological surfaces.

(9) The adopted solution should promote the sustainable development of the Valley.

(10) The proposed intervention should not be out-of-date in short time, with respect to adopted technologies.

But also, the Charter of Venice should not be disregarded. Main relevant articles in conservation and restoration mention the following: making use of them for some socially useful purpose; preserving a setting which is not out of scale; where traditional techniques prove inadequate, the consolidation of a monument can be achieved by the use of any modern technique for conservation and construction, the efficacy of which has been shown by scientific data and proved by experience; the valid contributions of all periods to the building of a monument must be respected; and replacements of missing parts must integrate harmoniously with the whole, but at the same time must be distinguishable from the original.

Finally, another important element is the wish of local community, the real owners and defenders of the Bamiyan Heritages in the last 1,500 years. The many discussions held on site since 2002 clearly stated the importance of the statues on the history and tradition of local population. The idea to give them the statue back is surely a relevant point, also for the national government. Undoubtedly, the 
revitalisation of the site will represent an effective action against worldwide terrorism, whose interest is to cut the root of local populations from their culture and history.

As a matter of fact, considering the request of UNESCO to develop either a physical or non-physical revitalisation of the Eastern niche, working on the proposal, we came to the conclusion that more than one solution can be proposed, all of them satisfying most of the above constraints. It is opinion of the authors that there is also a third approach, which is the realisation of a temporary and removable structure, based on 3D augmented reality, which is in between the physical and nonphysical. Some ideas were then developed, starting from the most radical one till some proposals that are mediating between the need of not disregarding the real history of the site and also giving back the memory of the magnificence of the statues and cultural landscape.

The following are the conclusion of our work that can be identified in four different proposals.

\subsection{Proposal no. 1}

A school of thought is clearly related to the idea that any destroyed heritage, if it is not possible to reassemble the original pieces, e.g. anastylosis, cannot be avoided. This is clearly stated in Art. 15 of the Venice Convention that states: “... All reconstruction work should however be ruled out "a priori". Only anastylosis, that is to say, the reassembling of existing but dismembered parts can be permitted. The material used for integration should always be recognizable and its use should be the least that will ensure the conservation of a monument and the reinstatement of its form...".

As a consequence, after having cleared out the bottom from debris and constructed the proposed underground museum, no other action should be implemented in the niche. They should be left as they are, as an emblem of human irrationality, to future memory (Fig. 13).

Clearly the back wall must be completely restored, to avoid the fall down of any single piece of stone. Unfortunately, this is not completely possible, and a protective net is surely required.

\subsection{Proposal no. 2}

A simple and removable panel, with the image of Buddha statues before the destruction, was already proposed by Andrea Bruno after the destruction, a 2D fibreglass panel, covering the back wall but giving the impression of previous situation, and 


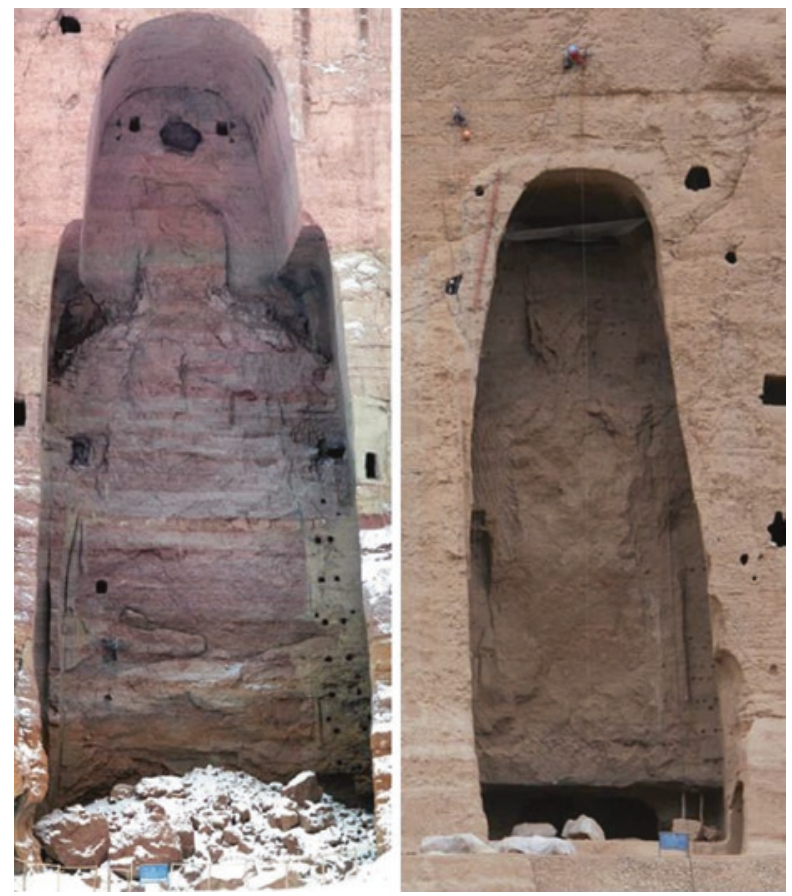

Fig. 13 Proposal no. 1: empty niches. (@ Claudio Margottini)

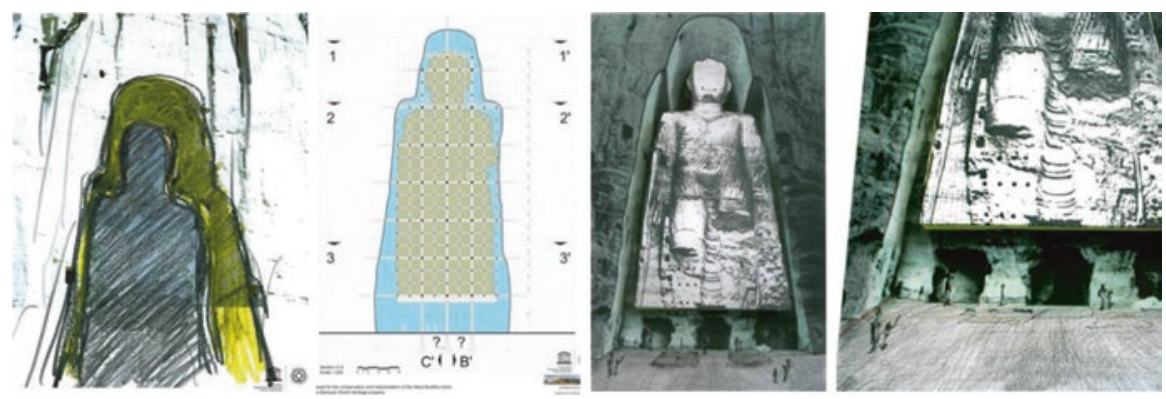

Fig. 14 Proposal no. 2: a 2D fibreglass panel on a supporting scaffolding. (@ Andrea Bruno)

very light and cheap, just requiring a scaffolding to build up. The panel is likely covered by sand, possibly the same Bamiyan sand. The design can be obtained from the many photos from Andrea Bruno's archive, and a low impact of the installation is easily achieved.

Figure 14 is reporting the idea, the supporting scaffolding, the design of the panel and a detail of it. 


\subsection{Proposal no. 3}

Our project intends to be a tribute to the Buddhist builders of the sanctuaries of the Bamiyan Valley, builders who were able to carve a very poor rock creating gigantic niches and images of a dimension which would guarantee the eternity of the work even if made from fragile stone.

While it was decided not to reconstruct the Great Buddha niche to maintain a lasting memory of the tragic event, it is proposed to partially reconstruct the small Buddha.

But the revitalisation/reconstruction has to be realised in a way which protects Bamiyan against the threat of future terrorist attack, and it must be easily distinguishable from the original cultural landscape. Finally, the reconstruction has to be fully reversible, and it may not modify the site permanently, thus emphasising the relevance of the OUV while adhering to criterion (vi), an approach, in any case, in line with the authenticity and integrity of the Bamiyan Cultural Landscape, as stated from the World Heritage Committee on 5 July 2003, which is also considering the war damage in Bamiyan's OUV.

In view of the above, it was decided that the Carrara white marble, which allowed Michelangelo's genius to create works which have become part of the world's human heritage, would convey to Afghanistan transferring a message of optimism, in the spirit of peace through the realisation of a new art creations of high spiritual and artistic value.

The identity of the project will be a very light marble shell, with a thickness of about $10-15 \mathrm{~cm}$, reproducing the original statue, giving the appearance of massive rock.

It will of course not be Michelangelo's hand to shape Carrara marble. This task will be entrusted by the last generation of robots, guided by expert hands of "craftsmen" who have already proven their outstanding craftsmanship on prototype elements, such as the Palmyra's Arch, symbol of "G7 of Culture in Florence, 2017." The marble shell will be created with state-of-the-art computer controlled machines and the world's largest anthropomorphic robotic arms that remove or carve material in our quarry marble in Carrara, properly modelled according to the most advanced geomatic 3D modelling methods, based on hundreds of historical photos and modern laser scanning.

The Buddha's expressive eyes will find, in this noble material, a new light that will again dominate the axis of the world that crosses the Bamiyan Valley as a symbol of a cultural continuity that has come to our day through the millennia.

This revival look will be a red line, linking the valley of Buddhas in Afghanistan with Carrara marble quarries in Italy.

The different steps of the project can be defined as follows:

(1) A 3D digital model of the Eastern Buddha statue has never been produced. Only Gruen and Hanush (2008) were able to partially reconstruct the Eastern Buddha surface by means of two old amateur images, taken before the destruction, newly made images of the now empty niche (acquired for the 3D modelling of 
the niche) and a given contour map, produced from the metric images of a past photogrammetric campaign of the University of Kyoto. Gruen et al. (2002) and (2004) applied, for the Western Buddha statue, a methodology similar to the one proposed in this project. In the present project, based mainly on new photogrammetric techniques, the use of historical photos coming from Andrea Bruno's archive, also integrated with other information to be collected worldwide (e.g. Switzerland, India, Japan), may offer a reliable background of information. Such data must be compared with a high-quality laser scanning survey, to be implemented on site, necessary to calibrate the old images. The selected images to be used for the 3D computer model are those taken from late 1960 until the destruction. The accuracy of a photogrammetric reconstruction of the statue depends to a large extent on the quality of the sourced images. In principle, photogrammetry can provide surface accuracies in the order of centimetres. If good-quality images, as stipulated in Chapter "Safeguarding and Preservation Activities at the Giant Buddhas and Other Monuments in the Bamiyan Valley 2004-2017", can be found, then the accuracy of the final model can be expected to be of this magnitude. However, accuracy will decrease with decreasing quality of the photography found and used.

(2) The 3D computer model will be used as input for giant CNC machines, already employed to reproduce the Palmyra's Arch in Syria when TORART presented a reproduction of a 1:3 scale of the triumphal arch, a symbol of the destruction carried out by ISIS, as part of the the Million Image Database project sponsored by the Institute for Digital Archaeology (IDA) in collaboration with UNESCO, the University of Oxford, the Museum of the Future in Dubai and the Government of the United Arab Emirates. The arch, displayed in significant spaces all over the world, is the "ambassador" of a new approach to archaeology, in which digital technologies used to carve marble and applied on an architectural scale reveal themselves to be an indispensable aid for restoring and integrating damaged and lost monuments. The sculpture of the new small Buddha will be very light; having a thickness of only $10 \mathrm{~cm}$ will totally weigh around 200 tons split in 120 pieces of approximately $1.600 \mathrm{~kg}$ each; for making it there will be a double curved carving that will allow to remove most of the material and keeping the necessary strength that is needed for stability criteria; all the parts will be easy to mount, remove and replace. TORART, through the most cutting-edge technologies, is able to translate any image into its three-dimensional shape with no limits for what concerns material or dimension and can be reshaped to make it completely customised, and it will be used to build, through machines, a true and authentic clone. Digitalisation of an element is essential to classify, restore or reproduce an artwork, by creating digital replicas of original pieces through a non-invasive way. The maximum precision and accuracy in respect of the real or virtual model, together with the ease to replicate an object, is obtained by using anthropomorphic robots that allow us, in different steps, to create also large works saving time compared to traditional techniques.

(3) Why marble? There are many reasons behind this choice: the need to fill a missing part of the landscape with an impressive "presence" and the precious marble, 
not any more sculptured by the hands of Michelangelo but from a high-tech robot, managed by Carrara artisans and artists who will excavate the rock from the same quarry as Michelangelo. This is representing the highest level of perfectionism that present technology may reach. There are also other elements which support the choice of marble. They include the need of differentiating original rock from modern replacement; the wish to insert the most precious in the most precious site of Afghanistan; and the importance of remembering the tradition of ancient Afghans (Fig. 15), very often wearing white coat to protect from them winter and then being similar to the white Buddha (see Photo).

In conclusion, with this proposal we put the most precious stone in the world, the Carrara marble, where once the most precious statue of Afghanistan was standing. The result will be an artwork of exceptional beauty, not altering the integrity and authenticity of the site, due to its reversibility, but creating a unique worldwide jewel, from Pietà by Michelangelo to Bamiyan Cultural Landscape, the same material symbolising the immortality of art, against any terrorism or destruction.

It is our opinion that, with this artwork, Bamiyan will become one of the largest attractions in the world, contributing to the security of the country and to an enduring peace.

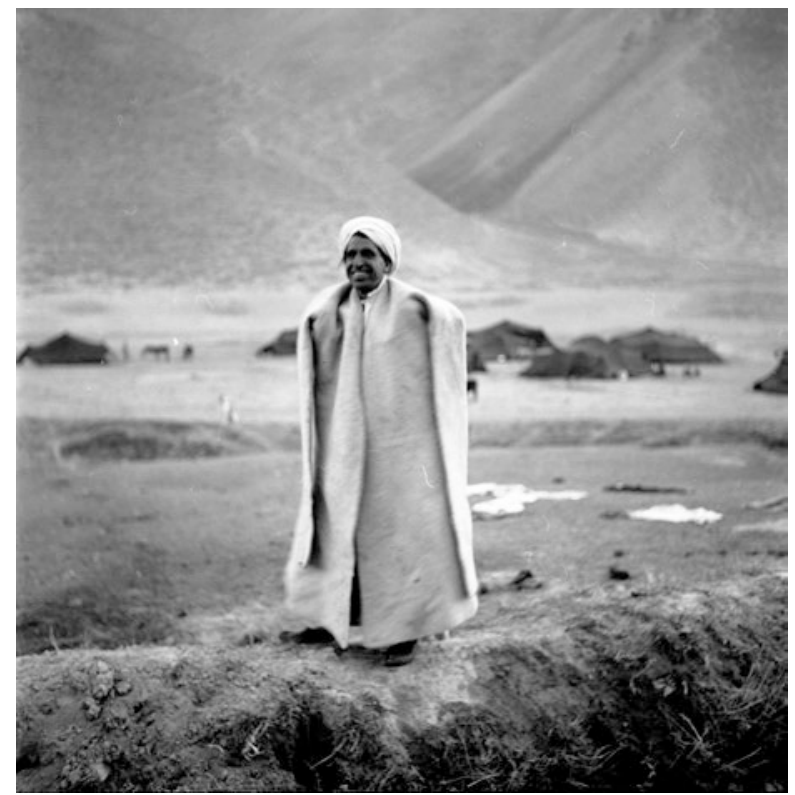

Fig. 15 Ancient Afghan dressing a white coat. (@) Andrea Bruno) 


\subsubsection{A 3D Visualisation of the Revitalised Buddha Statue (Figs. 16, 17,} 18,19 , and 20)

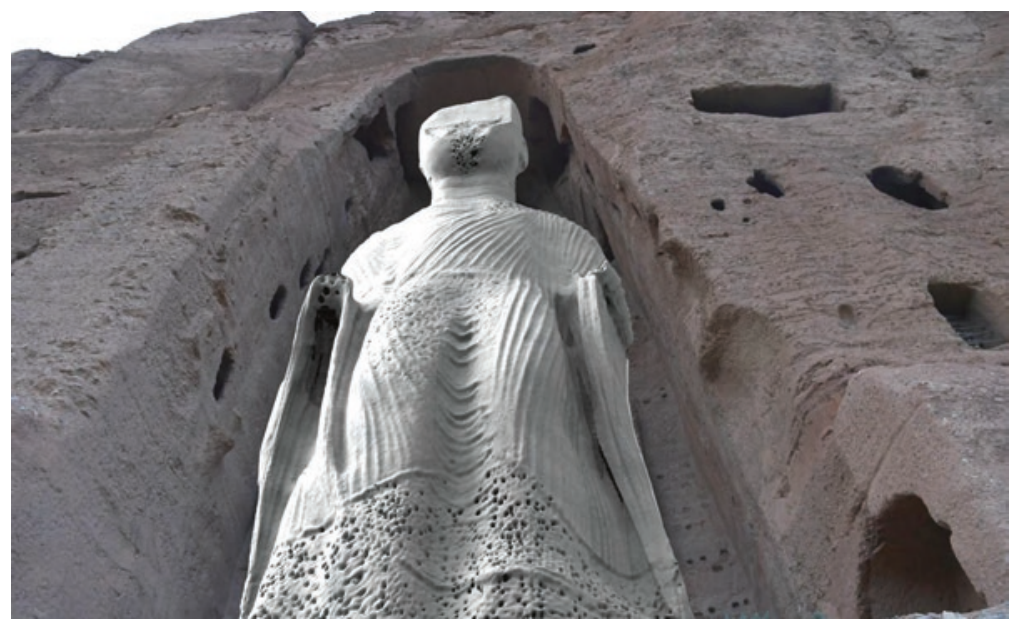

Fig. 16 The reconstructed 3D surface of Eastern Giant Buddha and the hypothesis of a shell in Carrara marble. (@ Filippo Tincolini)

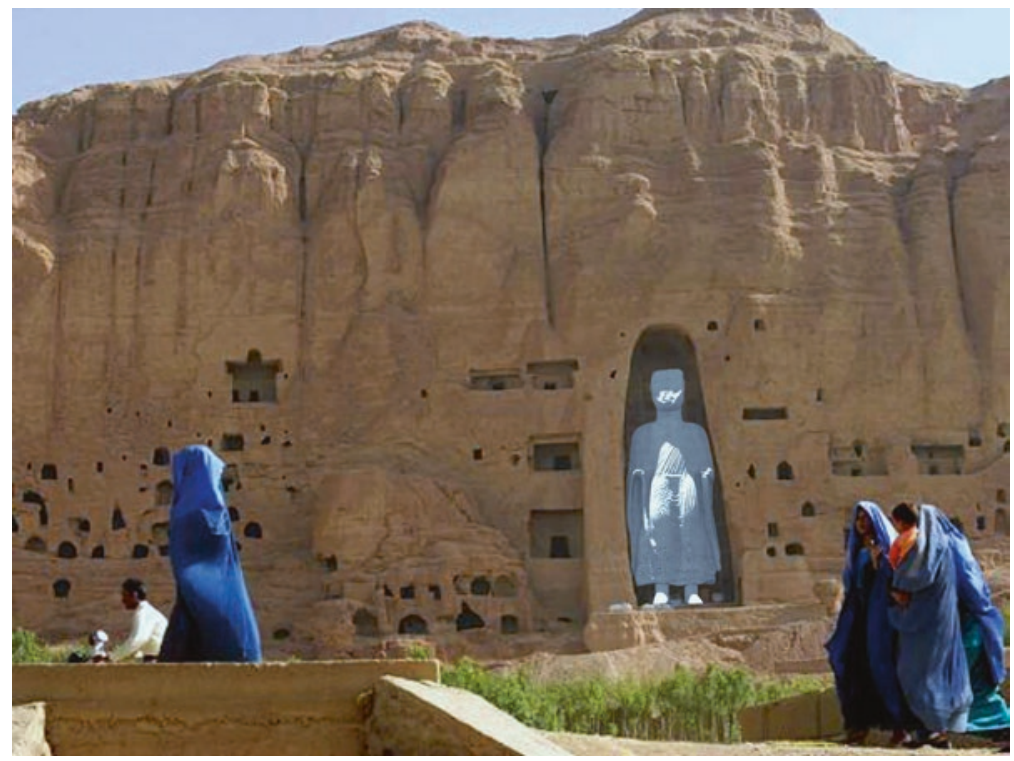

Fig. 17 The reconstructed 3D surface of Eastern Giant Buddha in the Bamiyan landscape. (๔) Claudio Margottini) 
Fig. 18 Detail of the 3D proposed reconstruction and cliff; frontal view. (C) Filippo Tincolini)

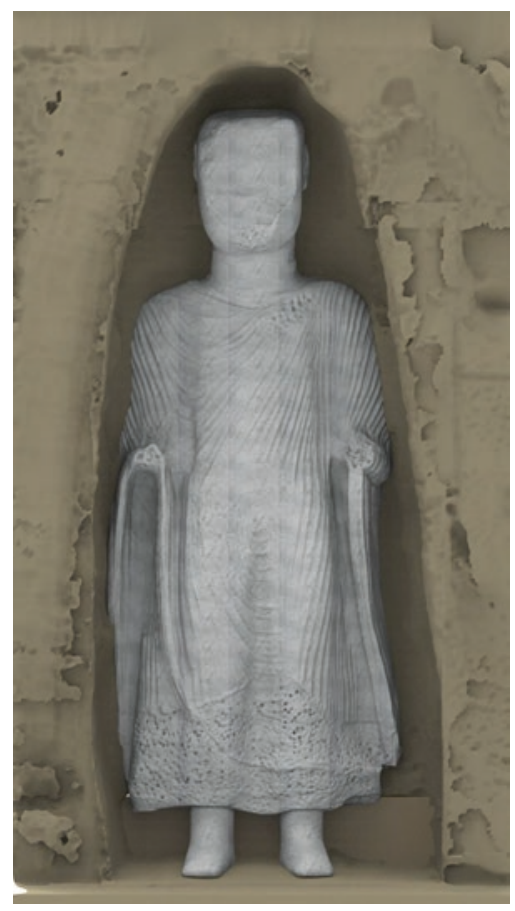

Fig. 19 Detail of the 3D proposed reconstruction and cliff; lateral view. (C) Filippo Tincolini)

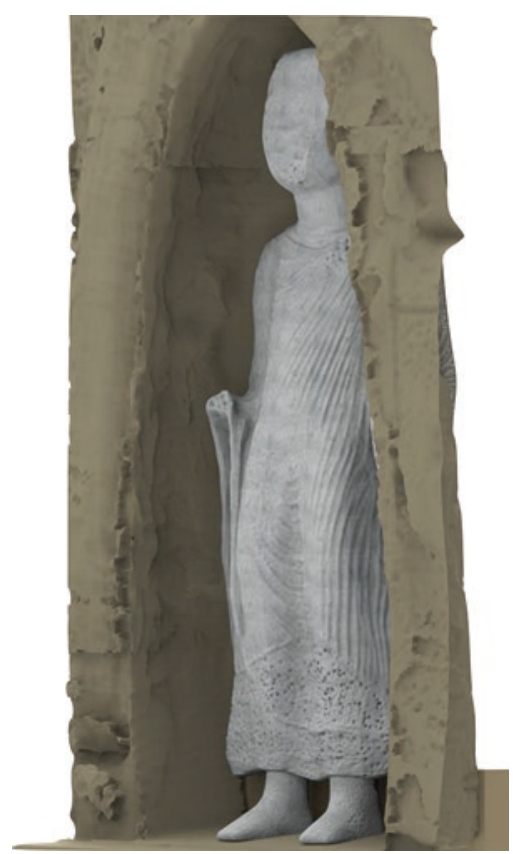




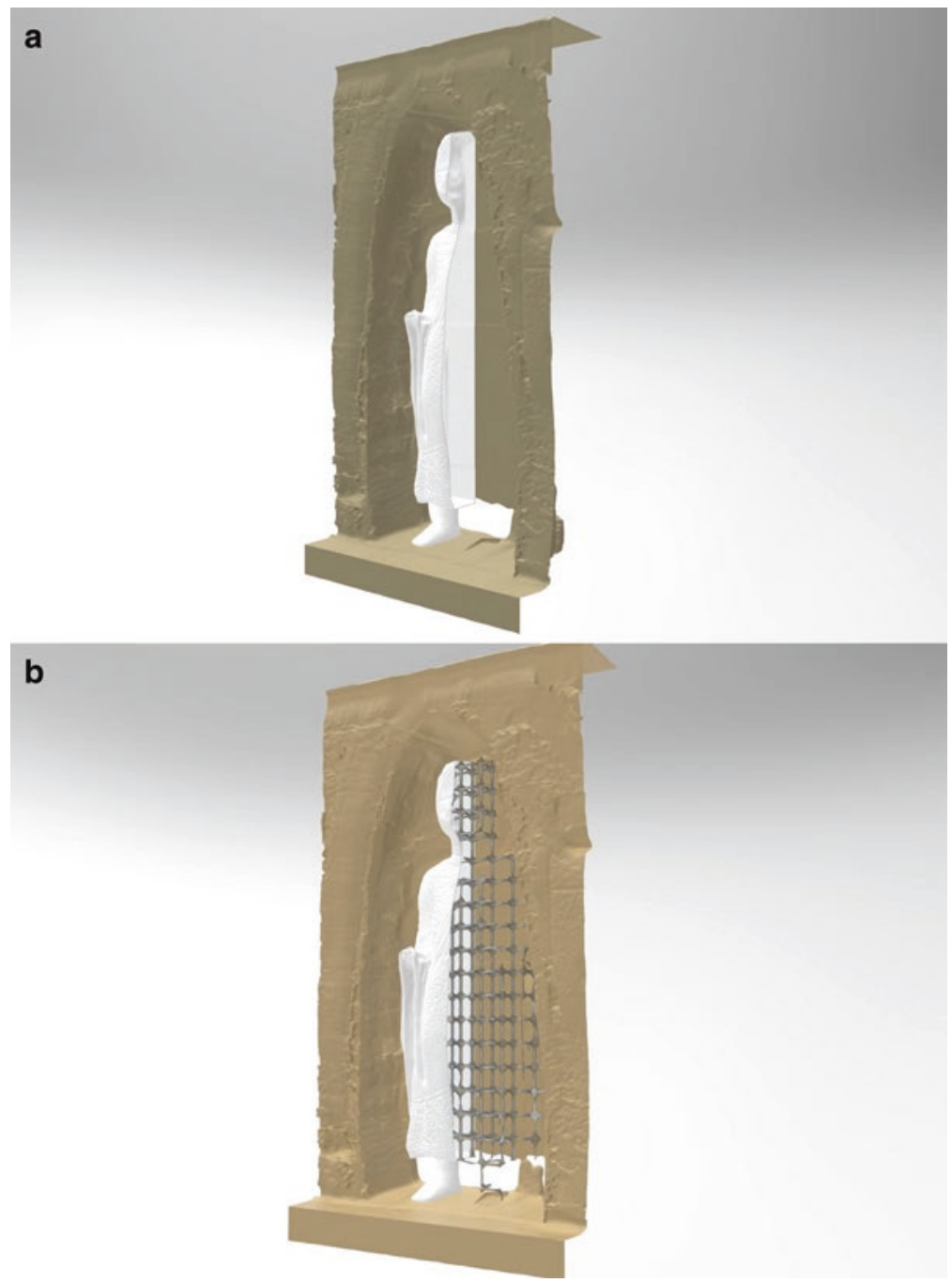

Fig. 20 Details of the 3D proposed reconstruction. (C Filippo Tincolini) 


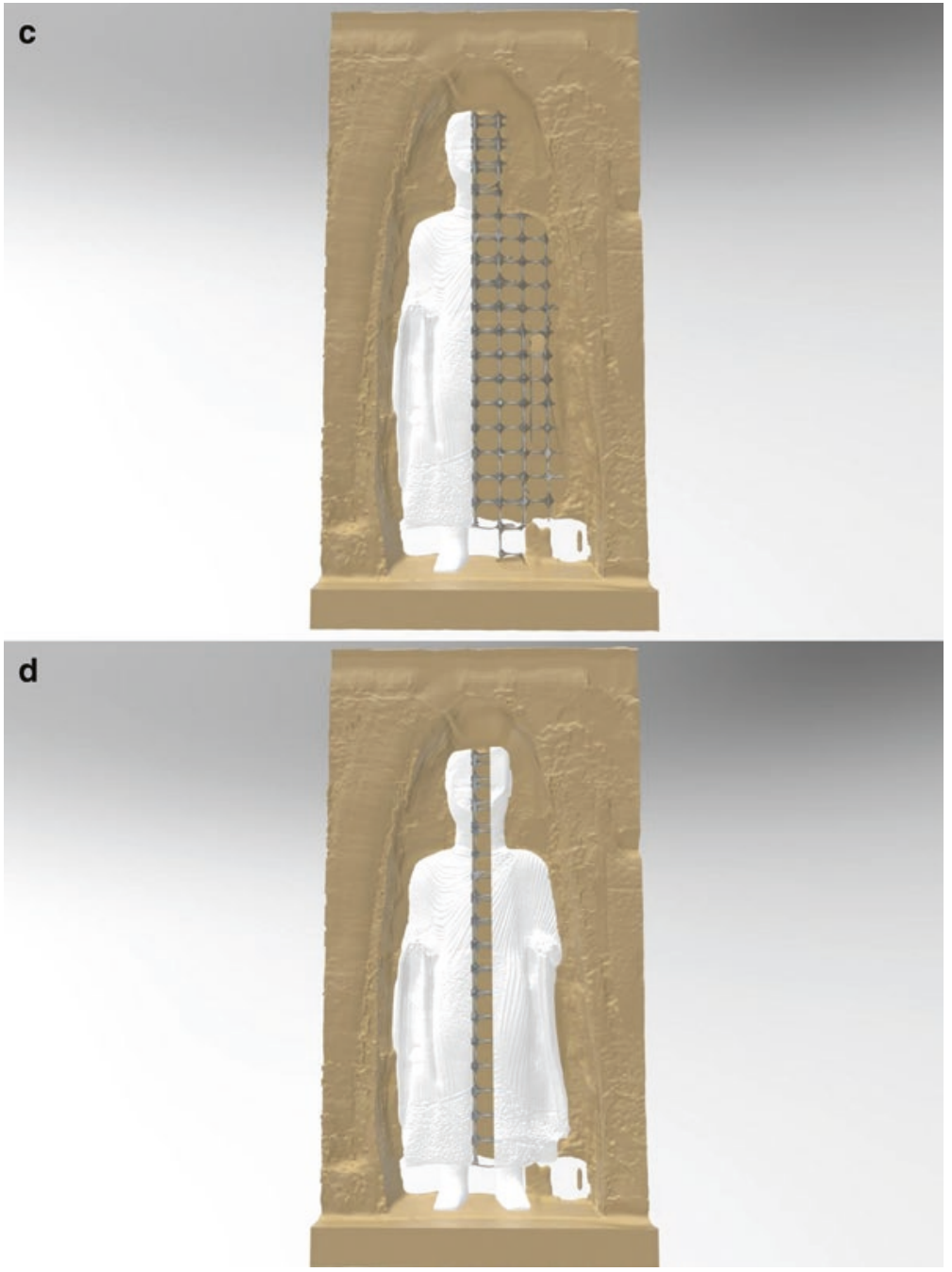

Fig. 20 (continued) 


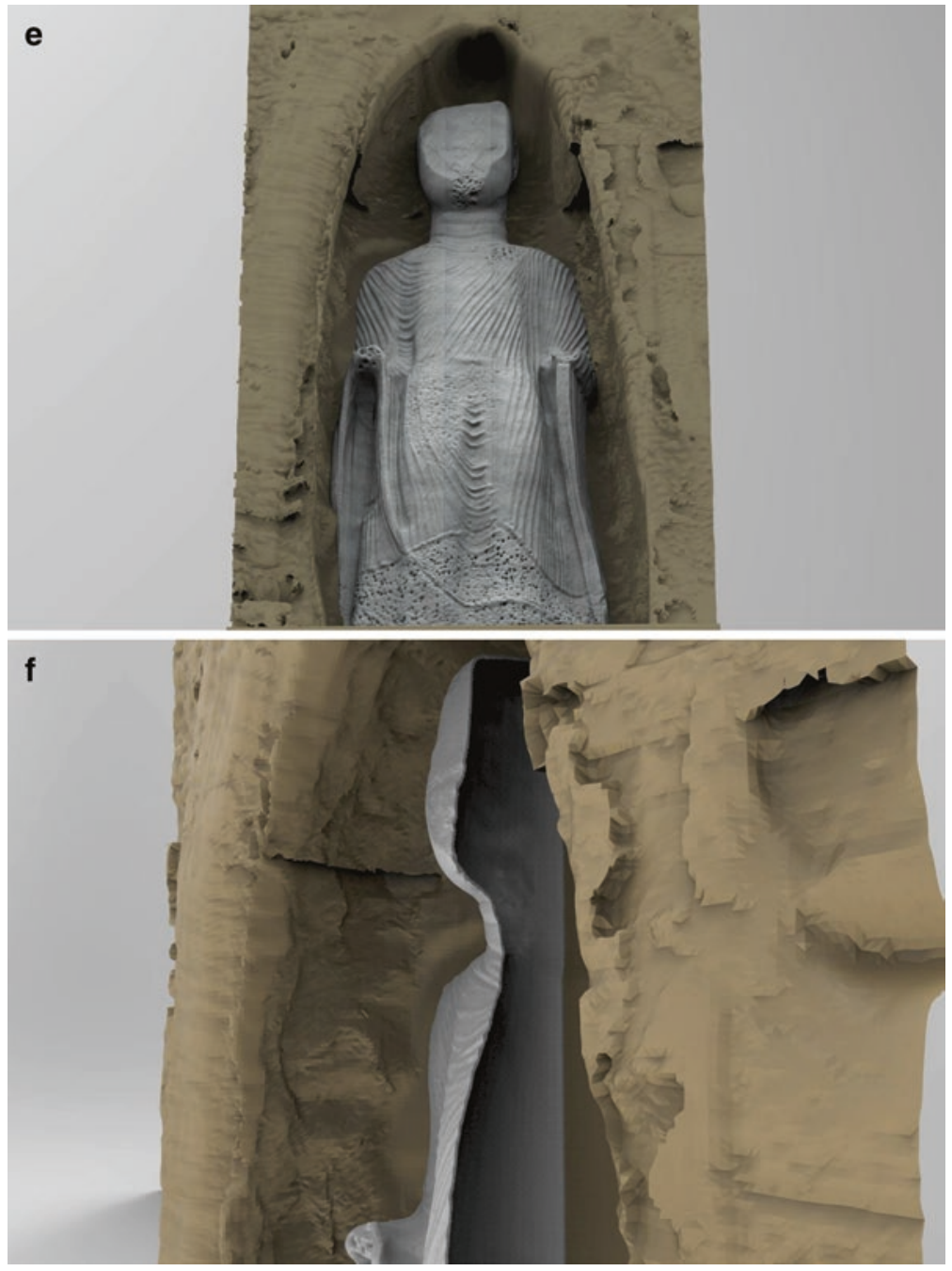

Fig. 20 (continued) 

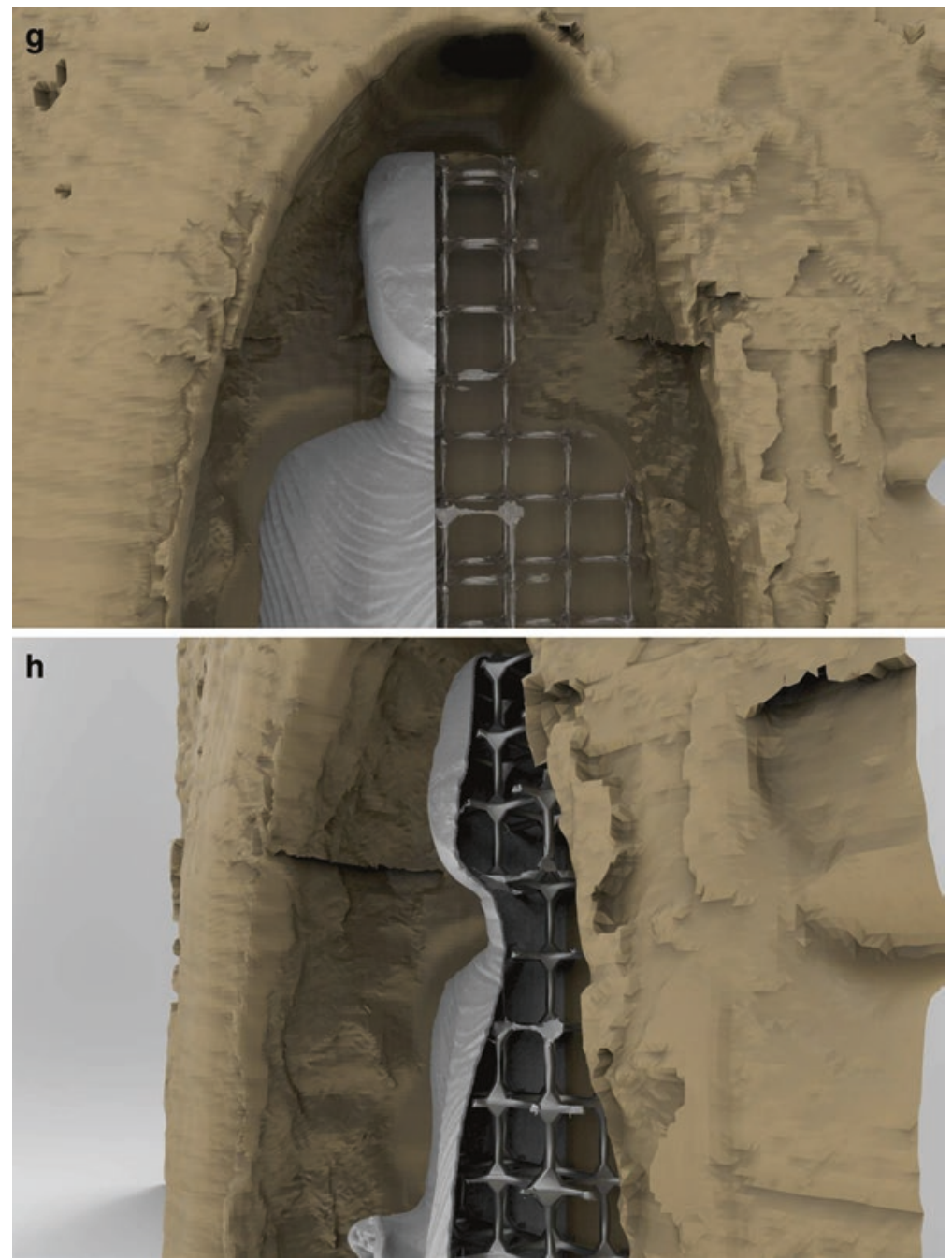

Fig. 20 (continued) 


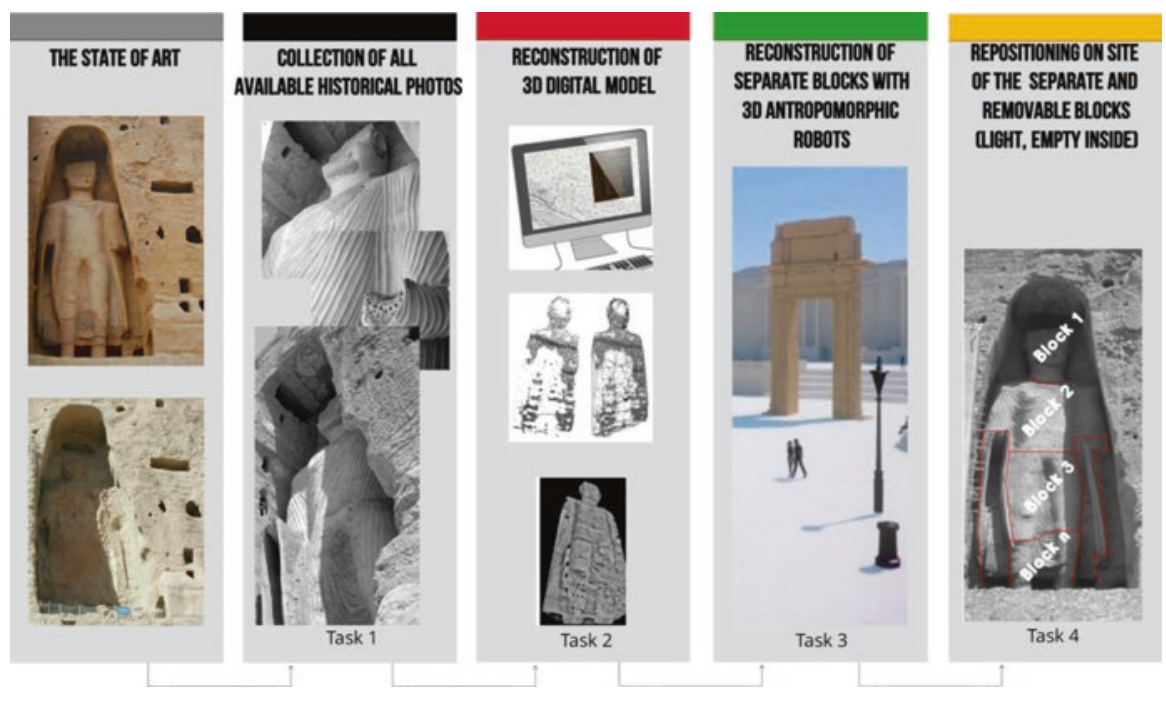

Fig. 21 Flow chart of proposal no. 3. (@ Claudio Margottini)

\subsubsection{Technical Details Regarding Material, Construction, Statics, Stability Against Earthquake and Other Environmental Constraints}

The present proposal is composed by five main tasks:

1. State-of-the-art and underground characterisation

2. The collection of historical photos (mostly coming from Andrea Bruno's archive)

3. Creation of a 3D computer model

4. Reconstruction of surface shell by sculpturing the famous Carrara marble with anthropomorphic robotic arms

5. Placing on site of the sculptured marble surface, supported by a proper metal structure (Fig. 21)

Following is a description of the different task/phases.

\subsubsection{State-of-the-Art, Underground Characterisation, Bearing Capacity and Seismic Input}

A project like the revitalisation of Eastern Buddha is requiring a detailed reconstruction of the underground conditions. In the past (Margottini C. 2014) major attention was posed to rock cliff properties. In this case it is necessary to investigate the underground rock mechanic properties as well as the possible presence of surrounding cavities.

Geophysical prospections will be conducted by means of georadar with different frequency antennas, and electric and seismic tomography. According to the above 
values results, a proper geognostic survey will be conducted with two boreholes. A number of boreholes will be as limited as possible, according to the information coming from geophysical prospections. Collected material will be analysed in geomechanical laboratory to identify the relevant geotechnical properties necessary for the correct choice and dimensioning of the foundation.

The reconstructed statue is apparently a massive block of marble but, due to the modern techniques of computer numerical control, is possible to obtain a surface shell with only a $10 \mathrm{~cm}$ thickness. This is making the final results extremely light, with respect to a full-size block of any kind of material.

In any case, considering $10 \mathrm{~cm}$ uniform thickness for the surface shell and over material for the anchoring points, according to the already realised $3 \mathrm{~d}$ model, the preliminary estimation is bringing to an estimated value of about $100 \mathrm{~m}^{3}$, from which a total weight of 280 tons.

In these conditions the footing of the statue will be an important issue.

According to the above values and considering the uniaxial compressive strength of rock that is, without considering the inner differentiation, siltstone and conglomerate, at lower about $6 \mathrm{MPa}$, with friction angle ranging between 28 and $42^{\circ}$ and density around 2,2 tonne $/ \mathrm{m}^{3}$, we can obtain, for soft rock, a bearing capacity of about 1,2 MPa, with Bowles (1977). According to this, the total weight of 280 tons can be supported by few $\mathrm{m}^{2}$. Being conservative it is possible to say that the bearing capacity can be assumed as $0,2-0,3 \mathrm{MPa}$ (about $20-25 \%$ of nominal calculation) and then requiring about $9,5-14 \mathrm{~m}^{2}$ of contact between the structure and the surface.

This is just a preliminary estimation to be confirmed with geophysical prospecting for the integrity of rock and laboratory test for rigorous shear strength parameters.

In any case, according to this value, it is possible to say that 9,5-14 $\mathrm{m}^{2}$ would be enough to sustain all the load of the proposed structure. Such contact surface between the statue and the soil can be obtained by removing the new feet constructed on 2013 and using the area external to the feet, to realise a concrete strip transferring the load of the new statue to the underground. According to the laboratory data, all solution will be investigated, also including the possible underpinning.

With this solution, the required bearing capacity is obtained and the inner part of the feet is preserved, in terms of integrity, since it is still part of the original archaeological remains.

In order to have a structure satisfying the safety conditions under seismic load, an earthquake risk analysis will be conducted. This will be developed with two different approaches: probabilistic and deterministic.

Probabilistic approach is based on the identification of surrounding seismic sources, attenuation path to the site, local ground response and, finally, the expected response spectra and/or peak ground acceleration for different return periods. In this case, the limit value of maximum credible earthquake will be considered (500 years return period).

The deterministic approach is based on the reconstruction of the possible waveforms (ground motion), generated at the site, by the maximum expected earthquake. After having defined the maximum expected earthquake, for instance, the earthquake of 9 June 1956, M 7.4 (Margottini C. 2014), the seismogenetic conditions of 
the source will be characterised (e.g. normal fault, hypocentral depth, etc.) and then the distance from the site and materials and finally the site conditions. The latter will be characterised in terms of shear velocity and geotechnical condition. Some of these information are already available from previous petro-geophysical investigations but the homogeneity of the depth must be further investigated (see. Margottini 2014).

From a seismological point of view, the ancient city of Bamiyan is located on the Herat fault, a 1200-km-long, east-west suture through Central Afghanistan that trends northward into the Hindu Kush mountains north of Kabul at its eastern end. The Bamiyan region is located in the transition zone between the intense seismic activity that characterises the Indo-Asian plate boundary in eastern Afghanistan and the largely inactive central part of Afghanistan. Ambraseys and Bilham (2014) describe 52 earthquakes that occurred in the period A.D. 734-2002; data for some centuries are unavailable, and only after the mid-nineteenth century does the earthquake record become more complete. Historically, the western Herat fault has remained largely inactive; however, a significant earthquake occurred near Bamiyan in 1956. The causal fault that slipped in this $M=7.4$ earthquake is not known although it appears to have occurred in the region bounded by the Herat fault and the Andarabad fault, $80 \mathrm{~km}$ to the north of Bamiyan.

Vibratory ground motion can be estimated by Iwasaki (2004) where the peak acceleration of the maximum historical earthquake of 1956 is considered about 0,1 g. Comparison was made also with potential damage (Margottini et al. 1992) and other hazards (Berardi et al. 1991) (Fig. 22).

\subsubsection{Collection of Historical Photos}

The ideal photography for photogrammetric applications should ideally have the following properties:
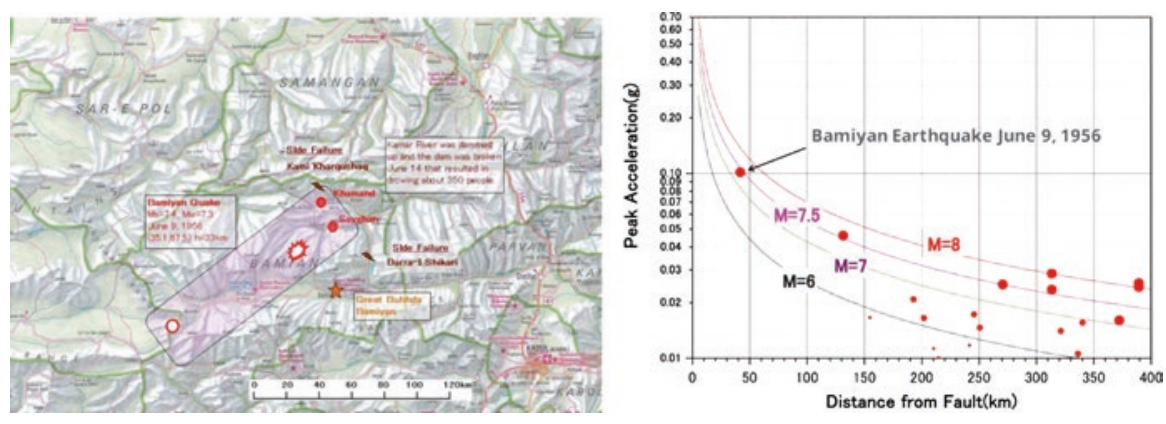

Fig. 22 Seismic zone in the Bamiyan region and a model of attenuation law. (Iwasaki 2004) 
1. The photography should have been acquired with a metric, i.e. a mechanically stable and calibrated, camera designed for photogrammetric processing.

2. All photos should be taken with the same camera, set to the same focal length.

3. The images taken should be the original digital or analogue images; they should not be modified digitally.

4. Analogue images should be scanned at a high resolution with a pixel size of better than 15 micron using a scanner with minimal distortion.

5. The images should be complete, i.e. the format should not have been changed reduced or modified in any way. This condition is the most crucial one, and any change to the original image format will render the photography unusable for photogrammetric processing, unless the largely forgotten mathematical model of DLT (direct linear transformation) is applied. However, the application of DLT does not guarantee a solution if the available photography differs too much from the ideal requirements listed here.

6. Photos fulfilling the requirement of an unchanged format can only be used reliably if the original format/border of the image is visible on the photo or if there is some other guarantee that the border of the photo does indeed represent the original full format.

7. Multiple photos covering all parts of the statue taken from different, geometrically well-distributed positions and angles must be available. The more images that can be found, the higher to chance of success.

\begin{tabular}{l|l|l|l}
\hline & Criteria for the photography & $\begin{array}{l}\text { Relevance for the } \\
\text { creation of the 3D model }\end{array}$ & $\begin{array}{l}\text { Likely availability of photography } \\
\text { which satisfies this criterion }\end{array}$ \\
\hline i & Metric camera & Ideal but not necessary & Highly unlikely \\
\hline ii & $\begin{array}{l}\text { Same camera and focal } \\
\text { setting for all photos }\end{array}$ & Ideal but not necessary & Highly unlikely \\
\hline iii & Unmodified image & Highly desirable & Possible \\
\hline iv & $\begin{array}{l}\text { Images scanned at high } \\
\text { resolution }\end{array}$ & Desirable & Unlikely \\
\hline v & Complete format & Highly desirable & Possible \\
\hline vi & $\begin{array}{l}\text { Visibility of the image } \\
\text { frame/border on the image }\end{array}$ & Highly desirable & Possible \\
\hline
\end{tabular}

The probability to find images which satisfy the above requirements is considerably higher for images sourced from museums, libraries and universities than for those collected from individuals via the Internet.

It is proposed that a number of leading libraries and universities in the USA and Europe are visited to search for appropriate images. Provisionally proposed are Harvard, the New York Public Library, the Smithsonian Libraries and possibly one of the libraries of San Francisco. In Europe, the libraries of the British Museum as well as libraries in Frankfurt, Berlin, London, Paris and Rome should be considered.

In the present project, existing photography can be sourced from: 

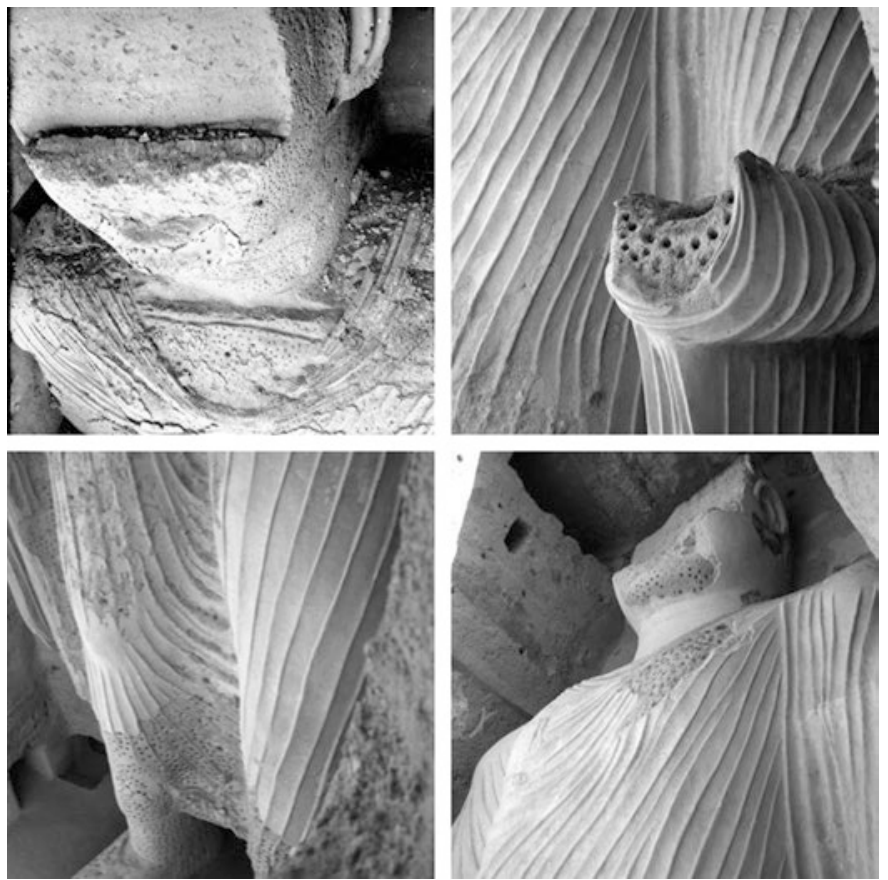

Fig. 23 Available historical photos. (@) Andrea Bruno)

i. Scientific collections in private archives (e.g. Andrea Bruno), libraries, universities and museums

ii. Internet search

iii. Invitations, through social media and/or other avenues, to travellers to submit photos taken of the Bamiyan Buddha statues prior to their destruction in 2001 (Fig. 23)

\subsubsection{Proposal of Method for the Creation of a 3D Computer Model of the Smaller of the Two Giant Buddha Statues}

The following proposal assumes that the most desirable, and possibly the only acceptable, physical reconstruction of the smaller of the two giant Buddha statues will have to be based on an accurate and authentic virtual reconstruction of the original statue. The approach to the creation of a 3D model of the Buddha by a combination of a photogrammetric analysis of historical images combined with laser scanning of the empty niche is proposed by the Principal Investigator of the Zamani research group at the University of Cape Town (www.zamaniproject.org).

The Zamani group considers itself qualified to carry out such a virtual reconstruction based on experience gained in the documentation of over 200 monuments and rock shelters in more than 60 sites in Africa and the Middle East. The 

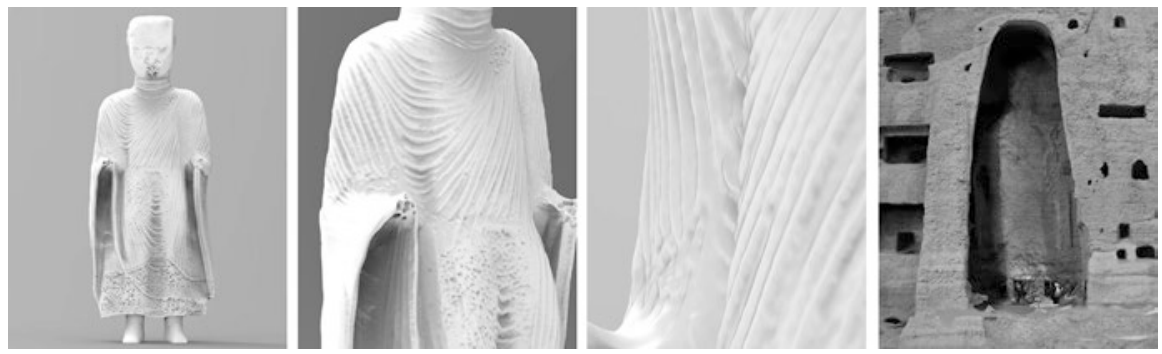

Fig. 24 Details of the reconstructed 3D model, obtained with few images and without making recourse to the large amount of available photos. (@ Claudio Margottini)

documentation work was carried out with or for institutions such as UNESCO, the WMF, the Getty Conservation Institute, the German Archaeological Institute as well as numerous international heritage experts and academics. Among the more important heritage sites documented by the group were Lalibela, Petra, Kilwa/ Songo Mnara, the Castles of Ghana and the Meroe Pyramids.

Detail on the use of historical photos has been given in the previous paragraph. Nevertheless, a preliminary model has been already reconstructed, obtaining the 3D computer model used in this preliminary proposal. Final work will allow the realisation of a more accurate 3D model (Fig. 24).

Figure digital model of Eastern Buddha statue and niche from available historical photos.

As the monument does no longer exist, laser scanning is obviously not an option, and one has to revert to photogrammetry instead, where laser scanning can be employed to provide auxiliary data.

Structure from Motion (SfM) would appear to be the most suitable photogrammetric method for a situation where little or no information is available about the nature of the photography.

First attempts by the Zamani group to employ SfM with a set of old photographs of the statue proved unsuccessful. However, the photos were probably modified and no longer had their original format (incorrect principal point) which makes them unsuitable for SfM processing. It is hoped that the search for "historical" images will result in a set of photos more suitable for the application of SfM.

It is also proposed that a brief field camping be carried out by two members of the Zamani team to acquire images of the rock face immediately adjacent to and inside the now empty niche. These new photos can then be combined with "historical" ones to support the SfM process.

The second objective of the field campaign would be the provision of control points next to the empty niche by laser scanning and total station surveying.

The laser scan model of the empty niche would also create a virtual reality environment combining the present niche with the replica of the statue.

While SfM, if successful, would be the preferred method because of its ease of data processing, it is advisable to allow for a second method to be employed if SfM 
fails or in combination with SfM. Direct linear transformation (DLT) comes to mind here as it is a method which does not require estimates for the orientation parameters of the cameras used nor does it require knowledge of the camera's principal point or fiducial marks. This would overcome the problems associated with the uncertainties regarding the properties of the available "historical" images. The shortcoming of the DLT method is that it does not result in point cloud data and only individual point positions can be determined by this method. The results of a DLT solution are typically very accurate and could be used in support of SfM or as a basis for a manual design.

It should be noted that none of the proposed methods will provide information on the shape of the back of the statue. This is because the space behind the statue appears too narrow to allow acquisition of photos suitable for SfM processing.

There can be no doubt that the proposed creation of an accurate virtual 3D model from "historical" photography is complex and beyond the normal application of photogrammetry. The quality of the results can therefore not be predicted, and success can subsequently not be guaranteed. The substantial experience of the Zamani team in the application of state-of-the-art technology to the documentation of heritage monuments should, while not guaranteeing good-quality results, have a good chance of producing an acceptable outcome.

\subsubsection{Reconstruction of Surface Shell by Sculpturing the Famous Carrara Marble with Anthropomorphic Robotic Arms}

TORART, a partner of this project, through the most cutting-edge technologies, is able to translate any image into its three-dimensional shape with no limits for what concerns material or dimension. The phase during which the shape is measured permits to keep the proportion of the object in a scientific way; once it is digital, it can be reshaped to make it completely customised, and it will be used to build, through machines, a true and authentic clone. Digitalisation of an element is essential to classify, restore or reproduce an artwork, by creating digital replicas of original pieces through a non-invasive way.

The adopted technology is not a 3D printer but a series of anthropomorphic robotic arms that are computer numerical controlled machines that removes or carves material arms. This equipment is likely the largest in the world and then the only one suitable to produce a sculpture with the dimension and the quality necessary to revitalise the Bamiyan site.

The robots used by the company originate from the very same experience of TORART and they are developed by ROBOTMILL, another companies of the same group, which takes care of designing, in addition to research and development.

This approach, after the reconstruction of Palmyra's Arch, will be applied to the Bamiyan Buddha, by using a novel material, the Carrara marble, suitable to enrich the site but also presenting a new approach to the site, avoiding the result of a fake archaeological place. 


\subsection{Placing on Site of the Sculptured Marble Surface, Supported by a Proper Metal Structure}

The external shell of the statue will be realised in Carrara and transferred by ship to the nearest port.

The inner part is composed by a special frame of stainless steel arms designed and constructed to support the special marble shell. The structure will be fixed to the rock by anchoring the frame, also contributing to the overall seismic stability.

Foundations will be designed after the geophysical and geological investigation. Thus, it is possible to say that the entire load of the structure will be transferred through the feet, which support a slab that is sustaining the entire structure. The bearing capacity, according to preliminary estimation, is ensured by $14 \mathrm{~m}^{2}$ of concrete foundation around the original feet, after having removed the construction of 2013.

Finally, the metal structure will be fixed to the back wall, to be more resistant to horizontal seismic action, by means of passive anchors. This is the same technique used to stabilise the niche in 2003-2007.

\subsection{Proposal no. 4}

The previous proposal no. 3 is revolutionary for the concept, even if completely removable, but also for the materials such as the Carrara marble. This solution could generate some criticism since the Carrara marble is not a local stone and the shining colour could be too decontextualised. To solve the above-described criticisms, an alternate solution has been considered, focusing on the selection of a different material. This could be local stone, a local marble, having the same colours of the Bamiyan cliff.

In this proposal the statue will be sculptured in Afghanistan, with anthropomorphic robots exported from Italy. At the end of the work, such robots could be donated to the local Afghan community, to maintain an ideal link between two quarry communities in Italy and Afghanistan (Fig. 25).

\section{Conclusion}

The present proposal is composed by an overall/modular approach with fixed elements (removal of fragments, little museums in front to each niche, geomatic survey of all cliffs) and four alternative solutions for the valorisation of niches.

The main proposals (Alternatives 3 and 4) are based on new advancement of science and technology applied to mining industries. 


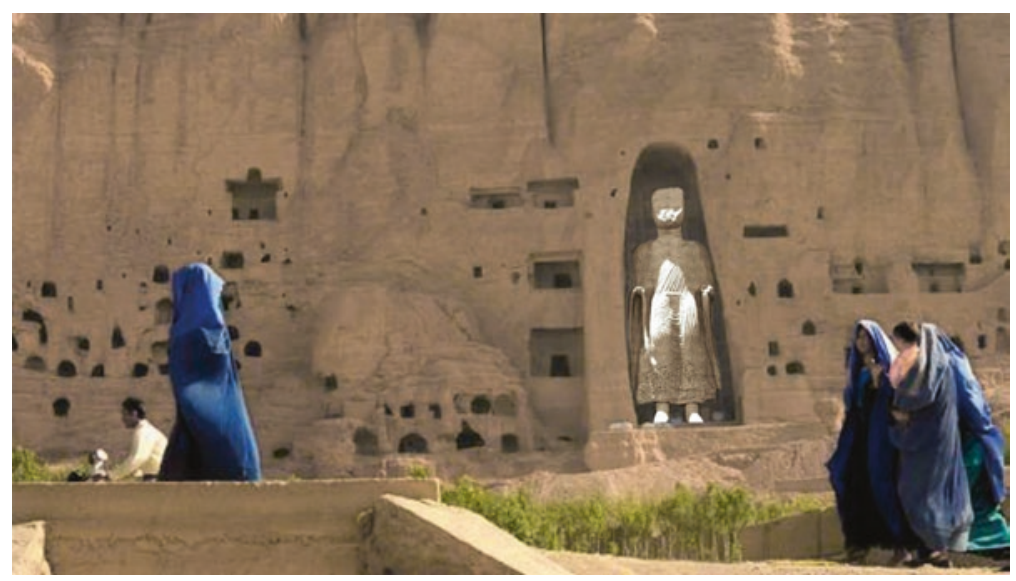

Fig. 25 Proposal no. 4: reconstruction of the shell of Eastern Buddha statue, by using a local Afghan marble. (@ Claudio Margottini)

The present proposal is generated from a high-resolution digital model obtained by recovering, scanning and elaborating of pictures of the statue taken in the same period and with the same camera. This is a new achievement of geomatic science, already demonstrated with the Palmyra's Arch, symbol of G7 for Culture of Florence (Italy) in 2017.

The proposal will also support the marble industry in Afghanistan.

\section{References}

Ambraseys, N.N. \& Bilham, R. (2014). The tectonic setting of Bamiyan and seismicity in and near Afghanistan for the past 12 centuries. In: Margottini, C. (Ed.), After the destruction of giant Buddha statues in Bamiyan (Afghanistan) in 2001 (pp. 101-152). Berlin, Germany: Springer-Verlag.

Berardi, R., Margottini, C., Molin, D., \& Parisi, A. (1991). Soil liquefaction: Case histories in Italy. Tectonophysics, 193, 141-164. ISSN: 0040-1951.

Bowles, J. E. (1977). Foundation analysis and design. New Delhi: McGraw-Hill.

Crippa, C., Granata, R., \& Margottini, C. (2013, May 30-31). Afghanistan, Buddhas of Bamiyan: Emergency consolidation of the cliff and niches. In (a cura di): E. Bilotta, A. Flora, S. Lirer, \& C. Viggiani (Eds.), Geotechnical engineering for the preservation of monuments and historic sites. London/Naples: Taylor \& Francis Group. ISBN: 978-1-138-00055-1.

Gruen, A., \& Hanush, C. (2008). Image- and model-based reconstruction of the small Buddha of Bamiyan, Afghanistan. International Archives of the Photogrammetry, Remote Sensing and Spatial Information Sciences, XXXVII (B5). Beijing.

Gruen, A., Remondino, F., \& Zhang, L. (2002). Reconstruction of the Great Buddha of Bamiyan, Afghanistan. International Archives of Photogrammetry and Remote Sensing, 34(5), 363-368.

Gruen, A., Remondino, F., \& Zhang, L. (2004). Photogrammetric reconstruction of the Great Buddha of Bamiyan, Afghanistan. The Photogrammetric Record, 19(107), 177-199.

Iwasaki, I. (2004). Geological setting of Bamiyan and geotechnical problem. UNESCO Meeting, 26 April 2004.

Margottini, C. (2004). Instability and geotechnical problems of the Buddha niches and surrounding cliff in Bamiyan valley, Central Afghanistan. Landslides, 1. ISSN: 1612-510X. 
Margottini, C. (2007). Engineering geology and cultural heritages: The conservation of remaining Bamiyan Buddhas (Central Afghanistan). In (a cura di): K. Sassa, H. Fukuoka, F. Wang, G. Wang (Eds.), Progress in landslide science. Berlin/Heidelberg:Springer, ISBN: 978-3-540-70964-0.

Margottini, C. (2009a). The consolidation and stabilisation of the Buddha niches and the cliff in Bamiyan /2003/04; 2006). In (a cura di): M. Petzet (Ed.), The giant Buddha of Bamiyan Safeguarding the remains (Vol. Monuments and sites XIX). ISBN: 978-3-930388-55-4.

Margottini, C (2009b). Recovery of the Buddha's niches and cliff in Bamiyan (Central Afghanistan) after the Taliban destruction of 2001. Key note lecture. In (a cura di): K. Sassa \& P. Canuti (Eds.), Landslides: Disaster risk assessment. Berlin/Heidelberg: Springer. ISBN: 978-3-540-69966-8.

Margottini, C. (Ed.). (2014). After the destruction of Giant Buddha statues in Bamiyan (Afghanistan) in 2001. A UNESCO's Emergency Activity for the Recovering and Rehabilitation of Cliff and Niches. Berlin: Springer.

Margottini, C. (2015a). Engineering geology in shaping and preserving the historic urban landscapes and cultural heritage: Achievements in UNESCO World Heritage Sites. In Lollino et al. (Eds.), Engineering geology for society and territory - Vol. 8 - Preservation of cultural heritage. Proceeding of IAEG XII CONGRESS, Torino, September 2014. Cham: Springer.

Margottini, C. (2015b). The consolidation and stabilization of the Buddha niches and the cliff in Bamiyan (2003/04; 2006). Monuments and Sites, 19, 175-196.

Margottini, C., Molin, D., \& Serva, L. (1992). Intensity versus ground motion: A new approach using Italian data. Engineering Geology, 33. ISSN: 0013-7952.

Margottini, C., Fidolini, F., Iadanza, C., Trigila, A., \& Ubelman, Y. (2015). The conservation of Shar-e-Zohak archaeological site (Central Afghanistan): Geomorphological processes and ecosystem-based mitigation strategy. Geomorphology, 239, 73-90.

Toubekis, G., Jansen, M., \& Jarke, M. (2017). Long-term preservation of the physical remains of the destroyed Buddha figures in Bamiyan (Afghanistan) using virtual reality technologies for preparation and evaluation of restoration measures. In ISPRS Annals of the Photogrammetry, Remote Sensing and Spatial Information Sciences, Volume IV-2/W2, 2017 26th International CIPA Symposium 2017, 28 August-01 September 2017, Ottawa, Canada.

The opinions expressed in this chapter are those of the author(s) and do not necessarily reflect the views of the UNESCO, its Board of Directors, or the countries they represent.

Open Access This chapter is licensed under the terms of the Creative Commons AttributionShareAlike 3.0 IGO License (https://creativecommons.org/licenses/by-sa/3.0/igo/), which permits use, sharing, adaptation, distribution, and reproduction in any medium or format, as long as you give appropriate credit to UNESCO, provide a link to the Creative Commons licence and indicate if changes were made. If you remix, transform, or build upon this chapter or a part thereof, you must distribute your contributions under the same licence as the original. This publication is also available at the UNESCO Open Access Repository: https://unesdoc.unesco.org/

The designations employed and the presentation of material throughout this publication do not imply the expression of any opinion whatsoever on the part of UNESCO concerning the legal status of any country, territory, city or area or of its authorities, or the delimitation of its frontiers or boundaries.

The authors are responsible for the choice and the presentation of the facts contained in this chapter and for the opinions expressed therein, which are not necessarily those of UNESCO and do not commit the Organization.

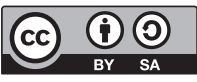

